\title{
EL TIMIATERIO ORIENTALIZANTE DE VILLAGARCÍA DE LA TORRE (BADAJOZ)
}

\author{
POR
}

\author{
M. ${ }^{a}$ LUISA DE LA BANDERA ROMERO Y EDUARDO FERRER ALBELDA \\ Dpto. de Prehistoria y Arqueologia. Facultad de Geografia e Historia. Universidad de Sevilla.
}

\section{APÉNDICE ARQUEOMETALÚRGICO}

\author{
POR \\ S. ROVIRA LLORENS \\ Museo de América. Madrid.
}

\section{RESUMEN}

Presentamos en este artículo un ejemplar excepcional de thymiaterion orientalizante procedente de Extremadura. Centran nuestra atención la descripción y el estudio iconográfico de la pieza, a la vez que replanteamos el análisis contextual y funcional de estos objetos en la peninsula ibérica.

\section{SUMMARY}

We present in this article an excepcional exemple of orientalizing thymiaterion from Extremadura. The description and the iconographic study of the piece centre our attention, as well as we state the contextual and functional analysis of these from the Iberian Peninsula again.

En un trabajo reciente abordábamos el estudio de los thymiateria orientalizantes en la península ibérica aprovechando la presentación de nuevos ejemplares (Bandera y Ferrer, 1992). En él haciamos algunas propuestas sobre la hipotética función social de dichos objetos después de valorar su tipología e iconografia y de analizar sus contextos arqueológi$\cos$. Sin duda los resultados a los que llegamos entonces se vieron condicionados por la escasa documentación existente y por lo fragmentario de las piezas, de manera que pusimos nuestras esperanzas en ulteriores aportaciones y en una documentación cualitativamente más reveladora. La oportunidad no se ha dejado esperar y contamos ahora con un panorama en parte modificado.

Estando ya en prensa el citado estudio tuvimos conocimiento de un nuevo timiaterio, excepcional en todos sus aspectos: buen estado de conservación, estructura casi completa, procedencia y circunstancias de hallazgo identificadas, aparte de su singularidad y belleza plástica (fig. 1). Si a estas características le sumamos los análisis arqueometalúrgicos a los que el quemaperfumes ha sido sometido, así como la posibilidad de identificar otras posibles piezas más a partir del nuevo ejemplar, creemos justificado un segundo acercamiento a la problemática generada en torno a estos objetos, en el estado actual de la investigación.

La pieza procede del término de Villagarcía de la Torre, al suroeste de la provincia de Badajoz, debiéndose el hallazgo a circunstancias fortuitas. Pero es más que posible la existencia en el lugar de un enterramiento por las lajas planas de piedra que al parecer - según se nos comentó- se encontraban próximas al timiaterio, y que probablemente podrían corresponder a una inhumación, dado el estado de conservación de la pieza y lo completo del conjunto.

\section{DESCRIPCIÓN DE LA PIEZA}

Desde el punto de vista técnico, el timiaterio es un bronce ternario compuesto por diversas partes fundidas en moldes «a la cera perdida», observán- 
doscen algumas de ellas en concrewo bajo la placa encular que soporta las tiguritas tres canaliflos para la inseccion del fundente. I t broncistase resefat como un experto artesano que ha sabido calcular con precision la cantidad de metal en funcion de un tamano rentable del crisol y de un numero determinado de moldes por colada. Isto explicaria las diferentes coladas observadas en los analisis. segun cuatro aleaciones distintas, que se basarian en lalores cuantitation ( $17 \mathrm{~d}$. Apendice). Sin embargo no duda en realizat alguna que otra "chapuzat" para solucionar un fallo producido en la base de la pieza. quizas por el peso o por problema de la fragua, que soluciona añadiendo tres trozos mas de bronce (con

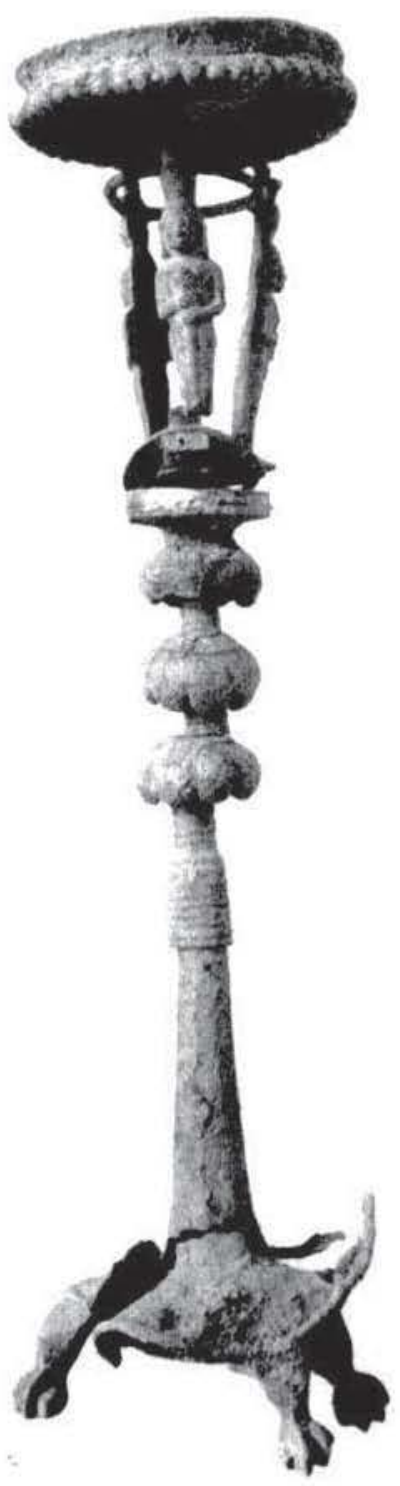

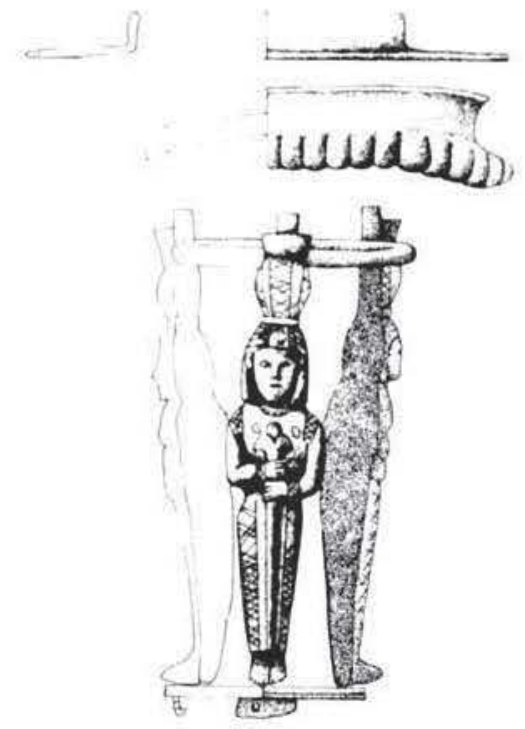
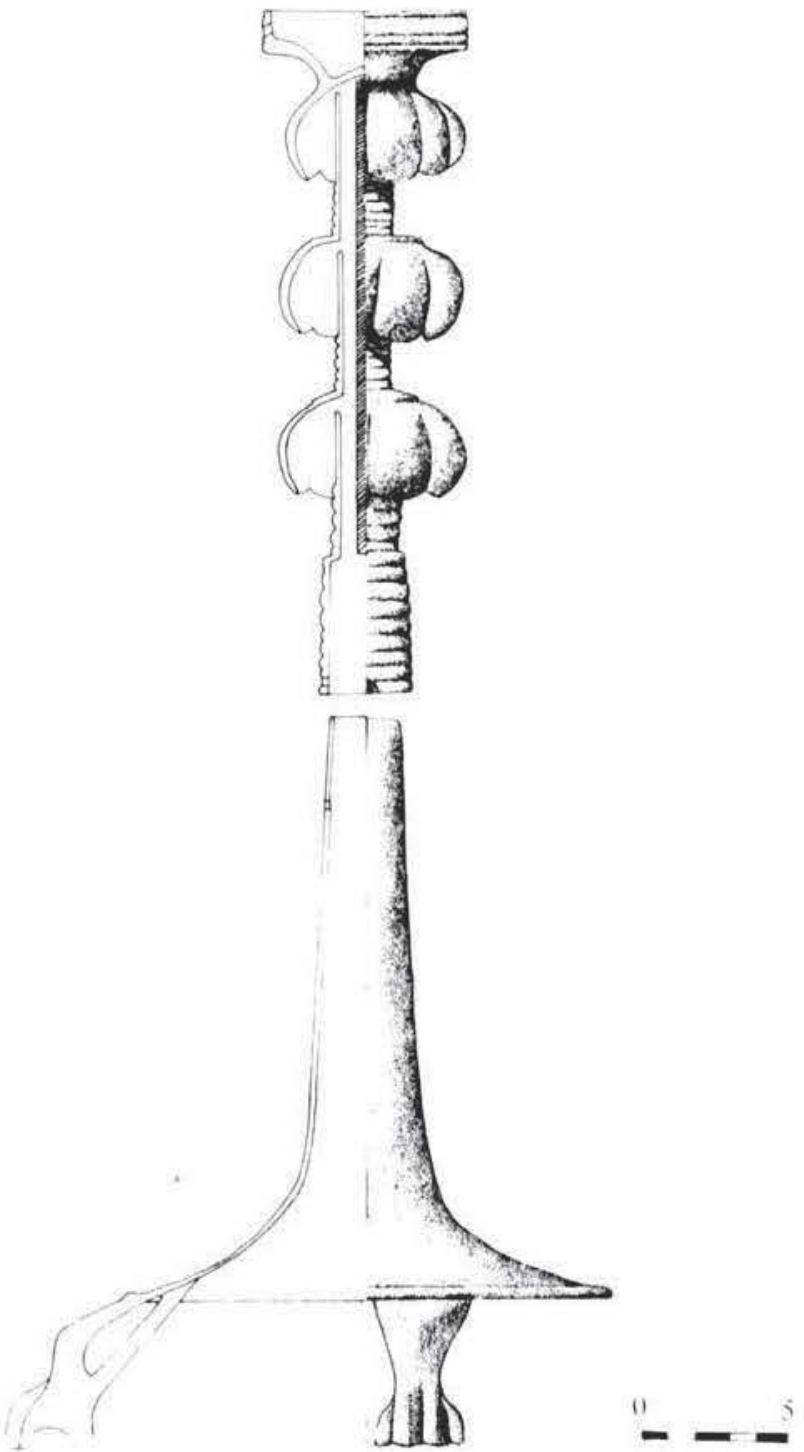

Figuras I y 2. - Timiaterio con cariátides de Villagarcia de la Torre (Badajoz). Foto de P. Witte. Dibujo con lia dispenseron de las distintas partes que lo componen. 

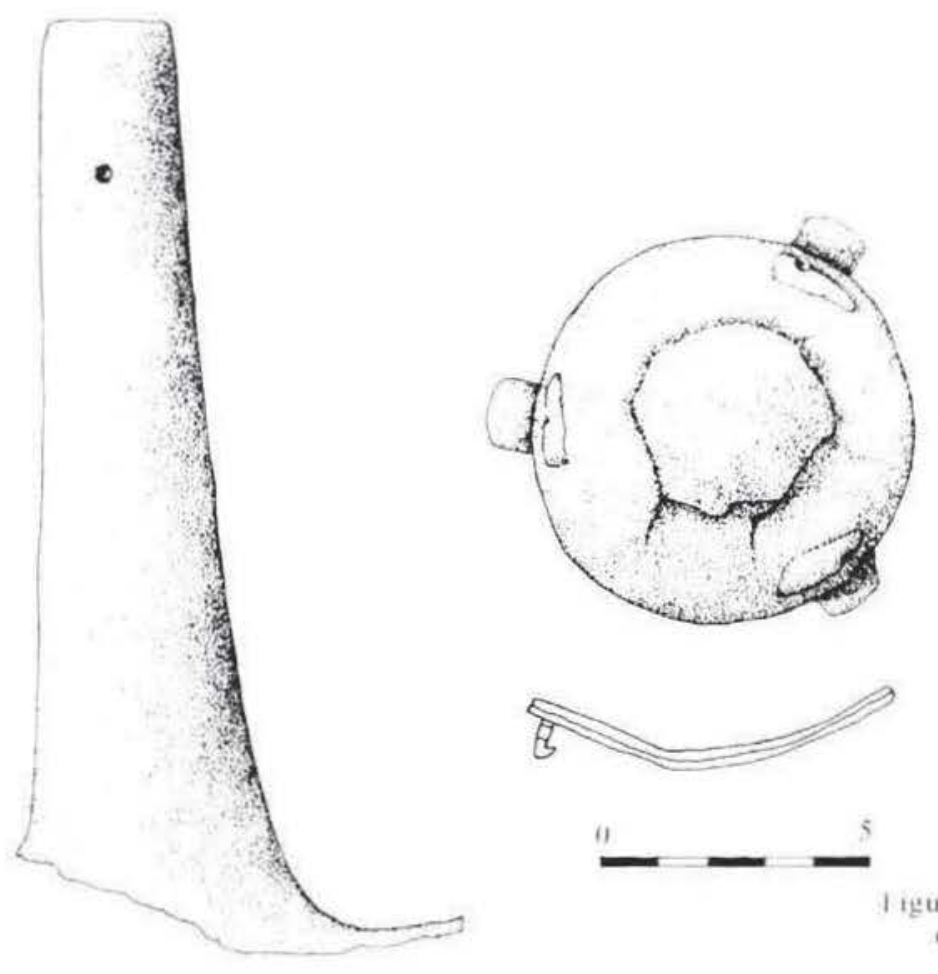
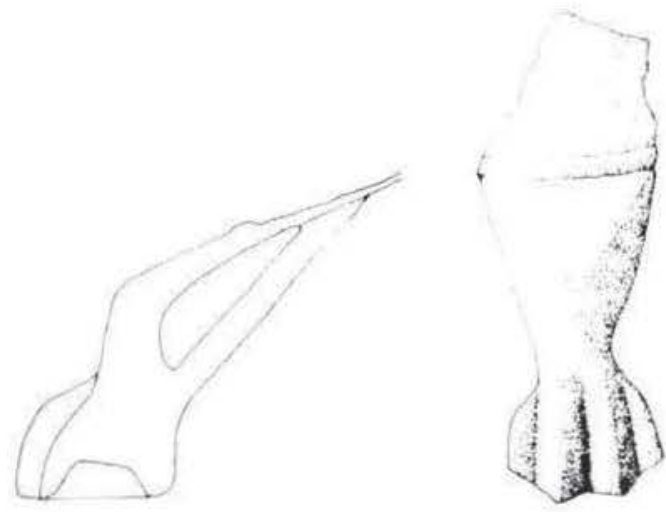

I teuras 3, 4 y5. Base del elemento soporte. base del capitel con carratides y garra de felino de la base y seccion un alto porcentaje de plomo) en la zona interior de la misma.

En el ensamblaje de las distintas piezas del timiaterio se han utilizado los sistemas de pasador. pestañas con remaches y machihembrado, pero no se han detectado procesos de soldadura. Otra técnica utilizada, observada al microscopio, es la del cincelado para determinar los rasgos anatómicos de las cariátides y los adornos del vestido y del tocado (figs. 9, 10.11).

Funcionalmente el conjunto se compone de dos elementos: un soporte, en el cual se distinguen tres partes definidas como pie, fuste y capitel; y el quemador. formado por la cazoleta y una chapa, sujeta a su perimetro por tres remaches, que to cubre en parte (fig. 2).

Formalmente, el timiaterio es complejo por el número de piezas que lo estructuran. De abajo hacia arriba, el primer cuerpo que encontramos es la base del elemento soporte. Lo forma una pieza cilindrico-cónica, hueca, en forma de trompeta invertida sostenida por tres garras de felino (figs. 2, 3, 5). El extremo superior es liso y presenta un orificio para el remache que lo aseguraba con la parte inferior del fuste. Por el contrario el extremo inferior. abocinado, se adorna con un engrosamiento de sección semicircular del que parten las garras de felino. Éstas son también de cuerpo hueco con cuatro dedos y llevan un vástago paralelo al desarrollo de la pata, que actúa de refuerzo (fig. 6). Toda la base fue fundida en una sola pieza, la peor conservada al recibir el gran peso del conjunto, lo que origino posiblemente su deterioro y rotura ya desde antiguo.

El fuste del soporte, que se superpone a la base. está compuesto por varias piezas independientes. que se ensartan en una barra de bronce maciza y de seccion circular que hace de cje (figs, $2,7,8$ ). La infe-

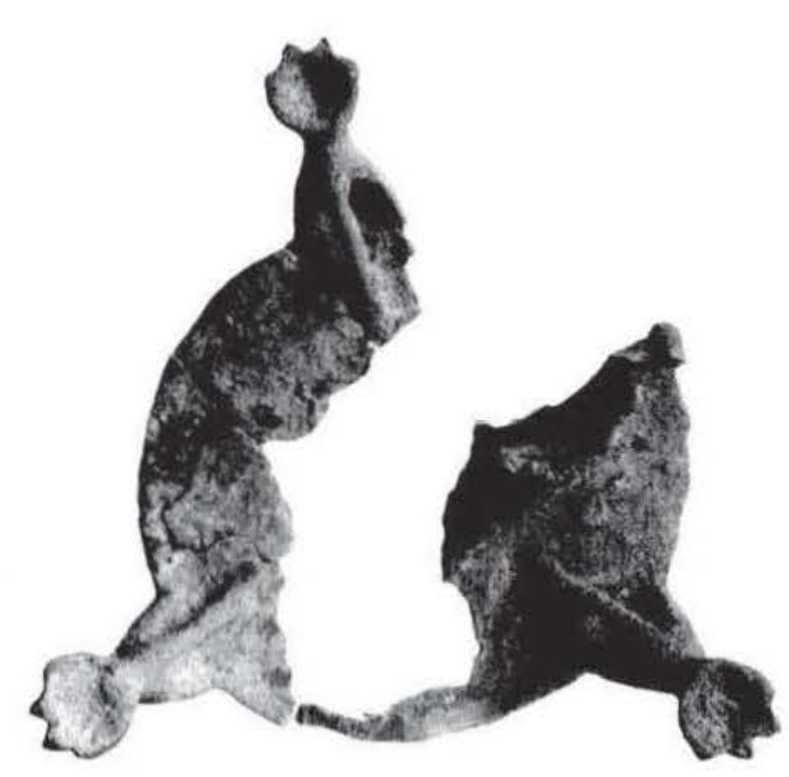

Figura 6. - Vista inferior del tripode de la base. Foto P. Witte. 

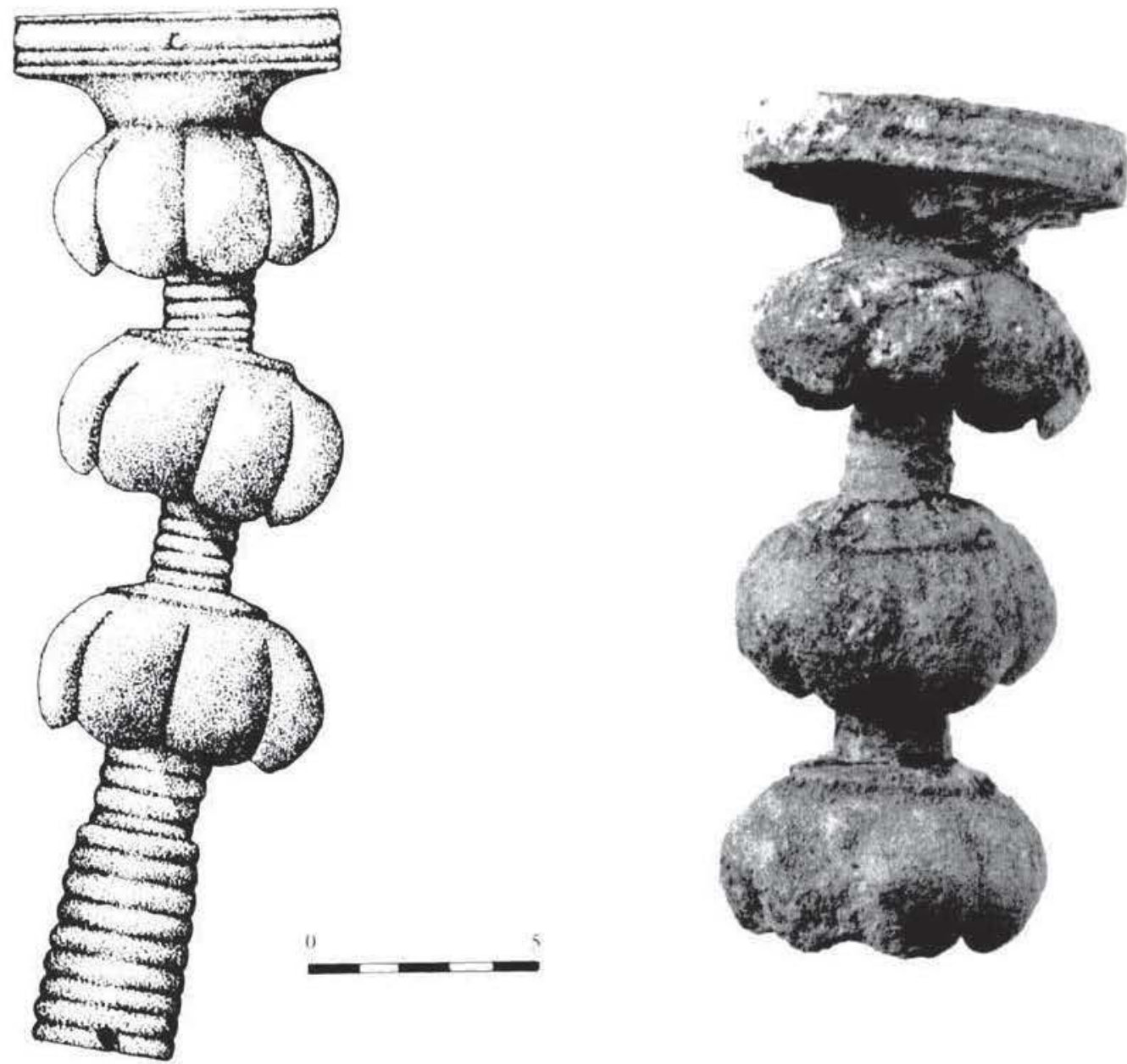

Figuras 7 y 8 . Fuste con hilas Dibujo. Foto P. Witte.

rior es una picza con dos segmentos tubulares de diametros distintos; uno mayor. correspondiente a la mitad inferior donde encaja la base, y otro menor en la mitad superior. El perfil exterior de la pieza es roseado en el tramo visible de la misma, y liso en la parte oculta por la flor de lila del cuerpo que se le superpone. Este y el elemento siguiente son dos piezas iguales. Ambas son cilindricas, con la mitad superior lisa y el perfil externo roscado en la mitad inferior, en cuyo borde se abren los ocho sépalos de lila. Como remate del fuste hay una cuarta pieza con idéntica floración y rematada en una moldura de gola, a la que se fija la barra-eje interior del fuste y en la que encaja un "capitel» con cariátides que es el que marca las diferencias más notables con todos los timiaterios orientalizantes conocidos hasta el momento (figs. 2, 8).

El «capitel», complejo en su composición, está elaborado en una sola pieza fundida en molde. En él hay tres partes perfectamente diferenciadas. La inferior es una chapa circular (refundida), con molduras laterales, de la que parten hacia abajo tres pesta- nas dobladas y con un pequeño orificio para introducir el remache que garantiza la sujeción de la pieza con la gola del extremo superior del fuste (figs. 2.4). Otra, intermedia, está formada por tres figuras femeninas dispuestas simétricamente con función de cariátides. Y por último. un aro macizo de sección circular enlaza las tres figuras a la altura de la cabeza (figs, 2, 9).

Las tres figuras son identicas. En actitud estante, sostienen una flor que germina entre sus manos (figs. 9, 10, 11), y están ricamente vestidas con una túnica larga y estrecha, de mangas igualmente largas y cuello cerrado, que deja ver los pies. En los bordes de las mangas y del cuello, en la zona de los hombros, asi como en dos franjas a lo largo de la falda, se disponen bandas rellenas con incisiones entrecruzadas que representan galones y bordados de malla. El cabello enmarca el rostro apoyando sobre los hombros y luce una banda central reticulada similar a las del vestido. Sobre la cabeza se dispone un remate floral de perfil bitroncoconico y exvasado, decorado igualmente con tres bandas verticales reticu- 

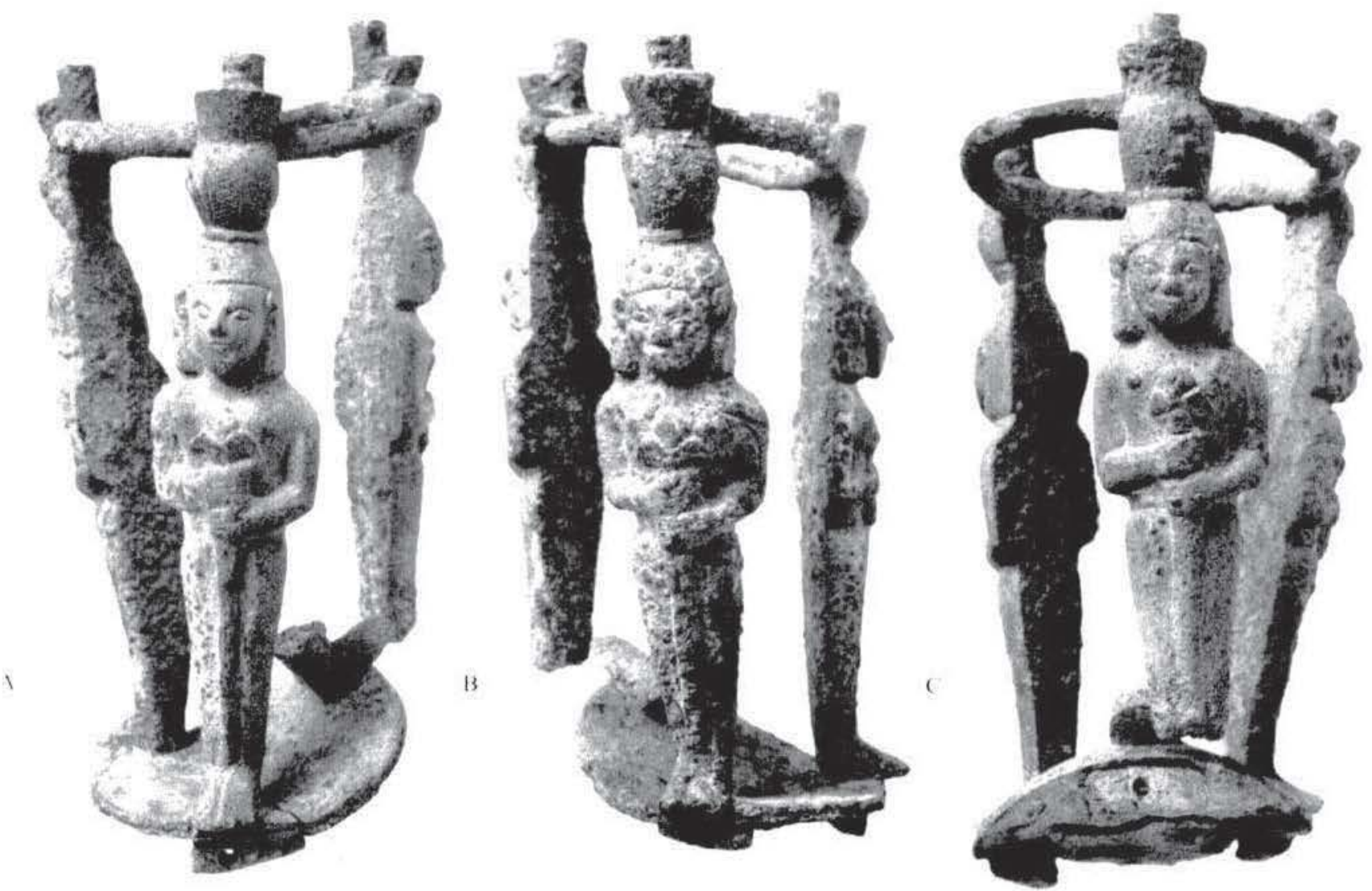

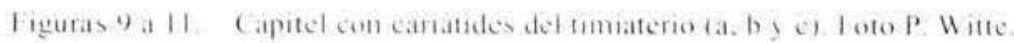
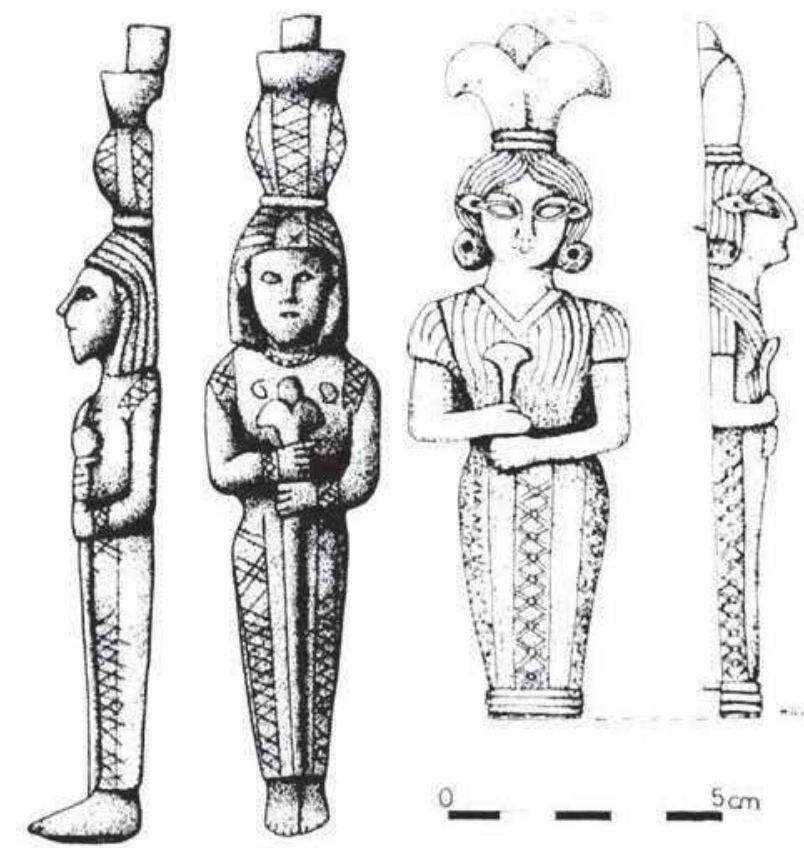

Figuras 12 y 13.-Cariatide de Villagarcia de la Torre (a) y de la tumba de Robarina (Cástulo). ladas y separado de ella por un collarino. Cada figura se remata con un pivote cilindrico macizo que encaja con el quemador por sistema de machihembrado.

Las cariátides tienen una concepción frontal, con relieve tan solo en el anverso y totalmente planas en su parte posterior, y con escaso interés por la representación de los elementos anatómicos: asi. los pechos se insinúan con simples incisiones circulares y las orejas, muy esquemáticas, han sido desplazadas por encima de los ojos hasta las sienes. La cara es angulosa, de nariz picuda y ojos almendrados, descuidando toda expresión armoniosa y estética.

En cuanto al quemador (fig. 14), es un cuenco de perfil quebrado, macizo y muy pesado, con tres orificios en la base y cuerpo gallonado con un total de 48 gajos radiales a manera de pétalos de una rosácea (fig. 15). Sobre él una pieza que lo cubre en parte, cuya función seria evitar que se desparramaran las brasas, y posiblemente servir de soporte a una tapadera calada que falta (fig. 16). Es una corona circular cuyo borde interior se eleva como una pletina. y con tres pequeños orificios en el perimetro exterior donde se insertaban los remaches que la sujetaban al borde de la cazoleta-quemador, de los que se conservan dos in situ (fig. 17). 

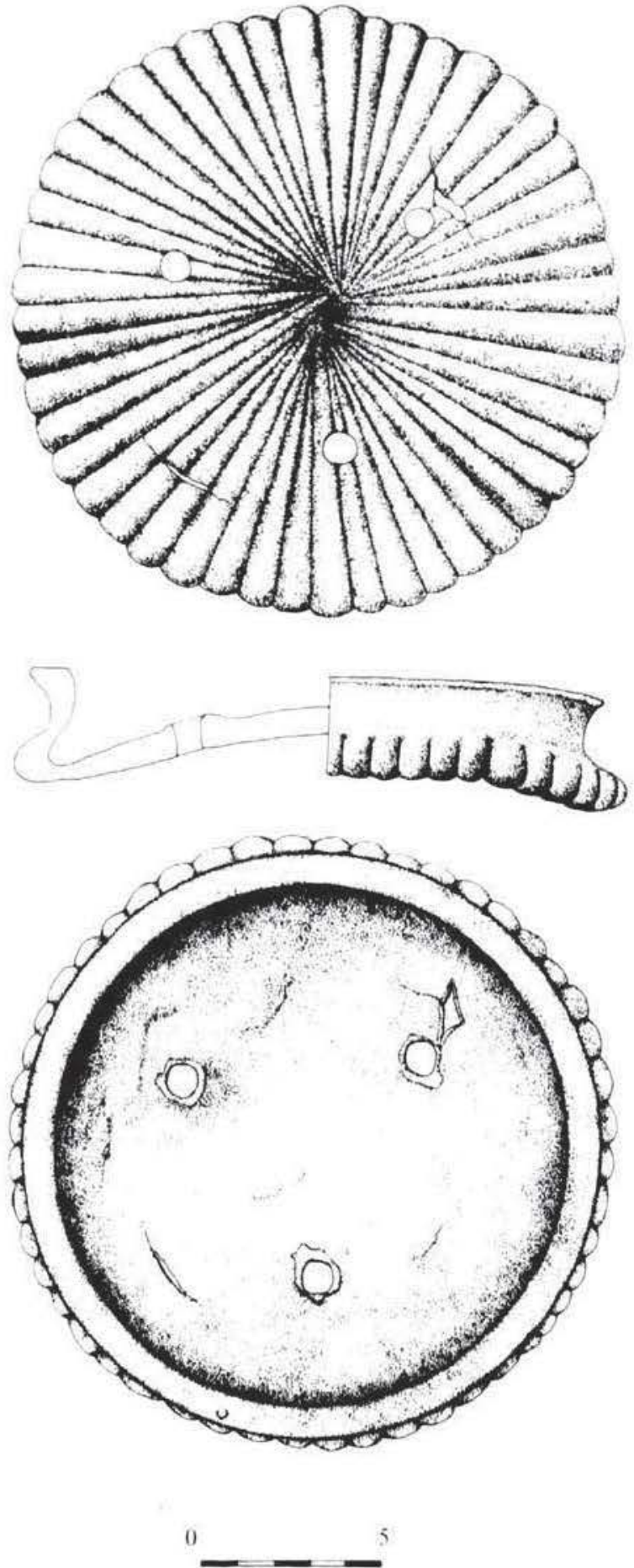

Figura 14. Cazoleta quemador del timiaterio.

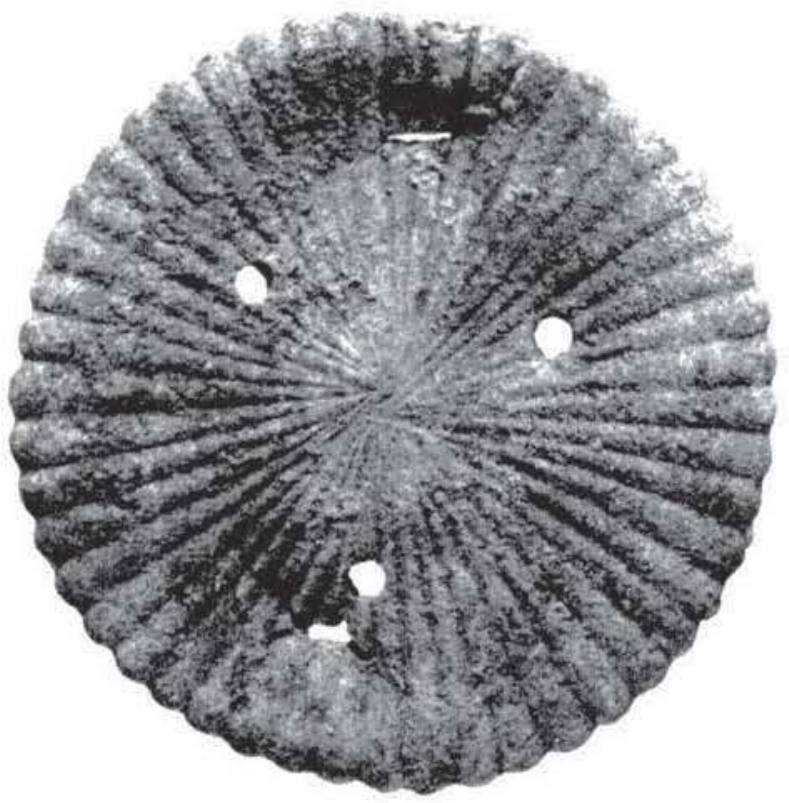

ligura 15 Vista inferior de la cazoleta quemador foro P. Witte

\begin{tabular}{|c|c|c|c|}
\hline Altura: & $60 \mathrm{~mm}$. & & \\
\hline \multicolumn{4}{|l|}{ fuste: } \\
\hline Dm. gola: & $71 \mathrm{~mm}$. & Dm. vástago: & $18 \mathrm{~mm}$. \\
\hline Dm. enchufe: & $31 \mathrm{~mm}$. & Girosor: & $3 \mathrm{~mm}$. \\
\hline Altura: & $225 \mathrm{~mm}$ & Peso: & $880 \mathrm{gr}$. \\
\hline \multicolumn{4}{|l|}{ cariatides: } \\
\hline Dur. base: & $72 \mathrm{~mm}$. & Dm. aro: & $790 \mathrm{~mm}$. \\
\hline (ir base: & $4 \mathrm{~mm}$. & Gir. aro: & $7 \mathrm{~mm}$. \\
\hline Altura: & $160 \mathrm{~mm}$. & Peso: & $\mathrm{x} 50 \mathrm{gr}$. \\
\hline \multicolumn{4}{|l|}{ cazoleta: } \\
\hline Dm boca: & $162 \mathrm{~mm}$. & Anch labio: & $10 \mathrm{~mm}$. \\
\hline Cirosor: & $8 \mathrm{~mm}$. & Dm orificio: & $8 \mathrm{~mm}$. \\
\hline Dm.mch: & $3 \mathrm{~mm}$ & Altura: & $35 \mathrm{~mm}$. \\
\hline Peso: & $1.250 \mathrm{gr}$. & & \\
\hline \multicolumn{4}{|l|}{ tapadera: } \\
\hline 1)mext.: & $160 \mathrm{~mm}$. & Dm. interior: & $86 \mathrm{~mm}$. \\
\hline Altura: & $12 \mathrm{~mm}$. & Grosor: & $1.5 \mathrm{~mm}$. \\
\hline Dm, orf: & $3 \mathrm{~mm}$. & Peso: & $200 \mathrm{gr}$. \\
\hline
\end{tabular}

\section{RELACIONES Y PARALELOS}

Ficha técnica

pie:

Dm. sup. $22 \mathrm{~mm}$. Dm. orificio: $3 \mathrm{~mm}$.

Grosor: $\quad 2.5 \mathrm{~mm}$. Gr. baquetòn: $7 \mathrm{~mm}$.

Peso: $\quad 1.080 \mathrm{gr}$. Altura: $\quad 175 \mathrm{~mm}$.
La adscripción del timiaterio a uno de los grupos que propusimos en la reciente ordenación tipológica de los timiaterios orientalizantes peninsulares (Bandera y Ferrer, 1992, 50 ss., fig. 3 ) es problemática, ya que comparte elementos aislados de los cuatro 

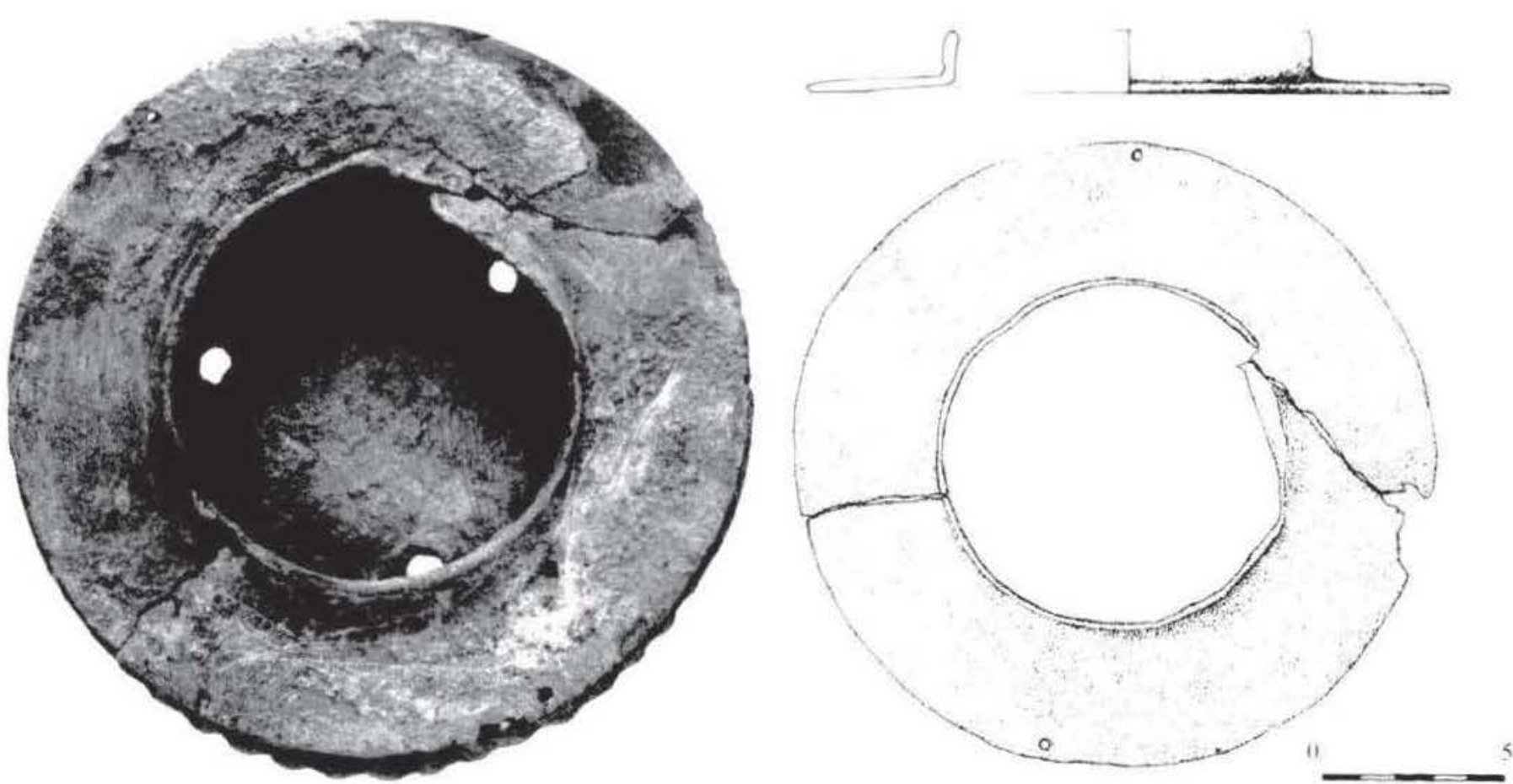

Figuras 16 y 17. Vista superior det quemador con la chapa soporte de la tapadera. Fofo P. Witte. Planta y seceton de la chapa soporte de tapadera

tipos que se diferenciaban: pero contrastando el tipo de bronce, la téenica de elaboración. el sistema de composicion del timiaterio y la decoracion. nos hemos inclinado por definirlo como una variante (Ilc) dentro del grupo II (Bandera. 1994. 426-427, fig. 2) y no come un tipo distinto.

En el análisis observamos que la concepción de la base en forma de tripode es similar a la del cjemplar de La Joya (Garrido y Orta, 1978. 97. fig. 57). pero mientras que en el timiaterio onubense adopta forma piramidal, de paredes lisas con molduras en los tres vértices y en los arcos que forman las garras (de cinco dedos). en el extremeño las garras sosticnen un cuerpo cónico, por lo que se relaciona igualmente con los timiaterios de Cástulo (Blázquě. 1975. 264 y fig. 10; Blaquez y Valiente, 1982, 417 y fig. 11), de la Walters Art Gallery de Nueva York (Blazquez, 1975, XCV. Lám. 95B), o del Cerro del Penón (Niemeyer y Schubart, 1965, 76 y fig. 1), todos con bases semejantes aunque sin tripode de garras. A esta serie de paralelos formales de la base se podria añadir también el soporte del thymiaterion hallado (junto con un jarro y un braserillo) en Las Fraguas (Talavera de la Reina. Toledo), del que sólo se tiene referencias por los dibujos de una memoria emitida por Jiménez de la Llave en 1860 , archivada en la secretaria de la Real Academia de la Historia de Madrid, y dada a conocer en publicaciones recientes (Maroto, 1990; Fernández-Miranda y Pereira ? 1992.65 y figs. 7.2 ); dato que nos permite situar un nuevo punto de dispersión en la cuenca del Tajo medio (fig. 18), el más norteno de los timiaterios orientalizantes peninsulares.

En cuanto a la tipologia de las patas de felino tenemos un paralelo procedente de Pancorvo(Montellano. Sevilla). con las mismas forma, medidas y estilo (Oria y otros. 1991. 177 y fig. 33. 3). Este yacimiento 2 en la comarea de la Sierra Sur de Sevilla. es un punto estratégico en la intersección de dos importantes vias de penetración desde la costa. una por el rio Guadalete, y otra que discurria cercana a Iptaci y que daria lugar con posterioridad a la via romana Corduha-Carteia (Corzo y Toscano. 1992). Otra garra identica se expone en el Museo Provincial de Cadiz procedente de las excavaciones de La Algaida en Sanlucar de Barrameda, Cádiz (Blanco y Corzo. 1983, 125). De suelo extremeño, y al parecer también de la provincia de Badajoz, procede un timiaterio cuyo soporte-tripode, si bien de estructura distinta, se apoya en garras de igual formato y

Los autores identifican el jarto del ajuar de l as Fraguas con el conocido como procedente de Nicbla, en el Metropolitan Museum de New York (pag, 63 ss) Nosotros, ante esta revision. Ienemos la sospecha de que el timiaterio de la Waiter Art Gallery proceda del mismo conjunto. por la semejanza de forma con el documenado en la Memoria.

Se trata de una acropolis natural que en el periodo orientalizante debio experimentar una ectosion del hábitat, a juzgar por los materiales conservados: fibula tipo Alcores, escarabco con leyenda egipeia, puntas de flecha orientalizantes (Velasco y otros. 1990. Mancebo y Ferrer, 1988-89; Id, 1992). 


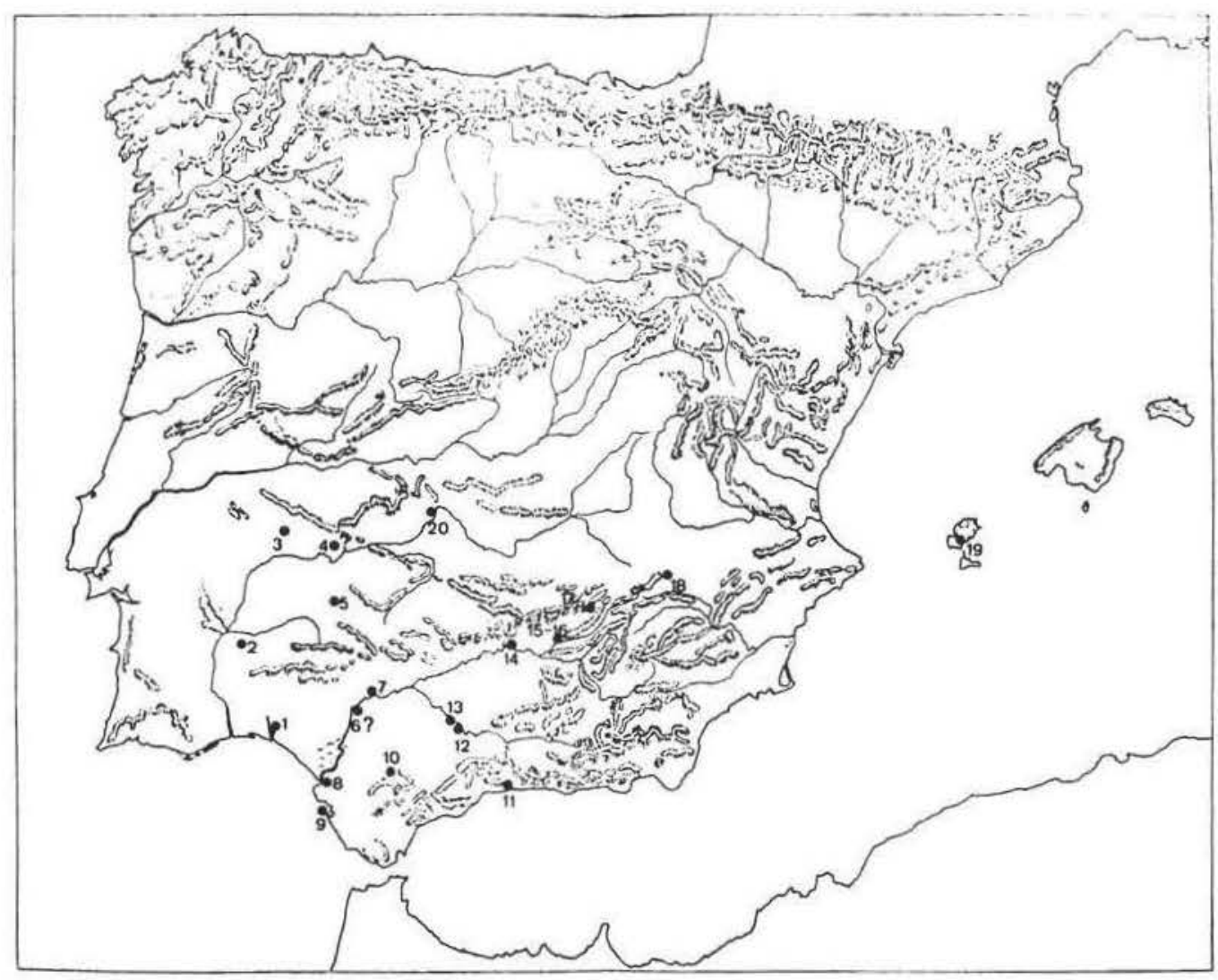

Figura 18. - Mapa de la peninsula ibérica con la dispersión de los timiaterios: 1) La Joya (Huelva) [Garrido y Orta, 1978] 2) Safara (Portugal) [Almagro-Gorbea, 1977] 3) La Codosera (Badajoz) [Garcia y Bellido. 1957: Almagro-Gorbea, 1977] 4) Colección Calzadilla (incierta) [lbidem] 5) Villagarcia de la Torre (Badajoz) [inédita] 6) MAP de Sevilla (incierta) [AlmagroGorbea, 1974] 7) Alcalá del Rio (Sevilla) [Olmos y Fernảndez. 1987] 8) La Algaida (Sanlủcar de Barrameda, Cádiz) [Blanco y Corzo, 1983] 9) Punta del Nao (Cádiz) [C. Blanco, 1970] 10) Pancorvo (Montellano, Sevilla) [Oria y otros, 1990] I1) Cerro del Peñón (Málaga) [Schubart y Niemeyer, 1965; Niemeyer, 1970] 12) Los Castellares (Puente Genil, Córdoba) [Bandera y Ferrer. 1992) 13) Alhonoz (Herrera, Sevilla) [López Palomo, 198Ia; Id, 1981b) 14) Los Villares (Andújar, Jaén) [Bandera y Ferrer. 1992] 15) Los Higuerones (Cástulo, Jaén) [Blázquez, 1975; Id, 1983; Blázquez y Valiente, 1982] 16) Estacar de Robarinas (Cástulo, Jaén) [Blanco, 1965] 17) MAN de Madrid (probablemente Despeñaperros) [Almagro-Gorbea, 1974] 18) La Quéjola (Albacete) [Olmos y Fernández, 1987; Olmos, 1991] 19) Puig des Molins (Ibiza) [M.J. Almagro, 1970] 20) Las Fraguas (Talavera de la Reina, Toledo) [Fernández-Miranda y Pereira, 1992].

medidas $^{3}$. Del santuario de Cancho Roano (Villanueva de la Serena, Badajoz) se documentan también dos garras similares, actualmente expuestas en el Museo Arqueológico Provincial de Badajoz, que, aunque por su tamaño debieron corresponder a otro tipo de objeto mueble, tienen un valor documental estimable para la posible determinación de taller o relaciones.

\footnotetext{
'Es una pieza de colección particular, inédita y actualmente en estudio, cuyo noticia agradecemos sinceramente al director del Museo de Badajoz, D. Guillermo Kurtz.
}

Con respecto al fuste (figs. 7 y 8 ) comprobamos que su morfologia es de aspecto similar a otros ejemplares peninsulares como los de Alhonoz (López Palomo, 1979; 1981a, 245; 1981b), Los Villares de Andújar (Bandera y Ferrer, 1992, 47, fig. 1), el del Museo Arqueológico Nacional de Madrid (¿Despeñaperros?) y el del Museo Arqueológico Provincial de Sevilla ( $¿$ Bajo Guadalquivir? AlmagroGorbea, 1974,42 , figs. 1 y 43 ; fig. 2 ), respondiendo todos a la misma composición de un enchufe cilindrico, encajado al pie y sujeto por un pasador, $y$ un fuste con dos o tres capiteles de sépalos de lilas (el superior rematado en gola moldurada y tres orifi- 
cios) que ensamblan con la parte superior: pero la elaboración y articulación denotan una proceso de realización distinta. Técnicamente el sistema de fuste segmentado en piezas independientes huecas, ensartadas en una barra maciza de la misma aleación (fig. 1), está más próximo al utilizado en La Joya, que a los soportes de lilas macizos y de sección octogonal que poseen aquellos otros. No obstante la desigualdad en la ornamentación del vástago, a base de estrias horizontales y otras particularidades, obligan a considerarlo como una variante dentro del mismo grupo (II), puesto que manifiesta los rasgos definitorios de clasificación del tipo, basados principalmente en la técnica de fundición de la pieza, en la unión de la base con el cuerpo intermedio mediante un pasador y en el ensamblaje del fuste con la cazoleta mediante tres perforaciones (Bandera, 1994, 426).

Como queda dicho, el cuerpo de las cariátides es el gran diferenciador de esta pieza por su novedad formal y por la información que nos trasmite de alegorias de carácter oriental que amplia la documentación conocida y enlaza con otras pervivencias posteriores.

Si partimos de un esquema formal, en la documentación peninsular las cariátides repiten con escasa variación el de las figuras hathóricas encontradas en la tumba de incineración de Estacar de Robarinas en Cástulo, hace ya algunas décadas (Blanco, 1965, 30ss. y figs. 19, 20, 21, 22, 31, y 47). Esas figuritas (también tres) tienen las mismas dimensiones y técnicas de elaboración, mantienen la misma actitud frontal con una flor entre las manos, en este caso un papiro sin tallo y lucen túnica con ajustada falda decorada por tres bandas verticales de bordado de malla, pero con mangas cortas y escote triangular. Las diferencias se marcan principalmente en el peinado, con dos bucles de extremos enrollados en espiral, en las orejas bovinas a la altura de los ojos como clara iconografia de Hathor; y también en el capitel que sostiene sobre la cabeza, esta vez en forma de lirio apoyado en doble collarino (fig. 13).

Aunque las tres cariátides de Cástulo se encuentran muy deterioradas por la acción del fuego, ello no nos ha impedido reconocer algunos otros elementos que llevan a reconsiderar la interpretación hecha por Blanco $(1965,39)$. Una revisión detenida y directa de las piezas ${ }^{4}$ indica que sin duda formaban

\footnotetext{
${ }^{4}$ En el Museo de Linares. Agradecemos a su directora, Dña. Concepción Choclán, las facilidades que nos proporcionó.
}

parte de un soporte de timiaterio como las cariátides del de Villagarcia de la Torre. Extraña en este sentido que no se puedan identificar otras partes tan sólidas y difíciles de deformar como el soporte, quizás de fuste con los capiteles vegetales, si bien podemos argumentar que, o no se quemaron con el difunto para ser reutilizadas, incinerandose sólo las figuras hathóricas por su posible carácter religioso: o que el thymiaterion no era exactamente igual al extremeño, a lo que contribuye el carácter orgánico de los diversos conjuntos documentados hasta la fecha, ninguno exactamente igual a otro. Sin embargo, hemos creido identificar la chapa sobre la que irian montadas las figurillas hathóricas, de caracteristicas y diametro similares a las del timiaterio extremeño, y la cazoleta que estaría realizada en chapa lisa sin decoración (Blanco, 1965, 28, 34 y 36 ; $y$ figs. 23,24 y 25 ).

La identificación realizada por Blanco como parte de un lebes de carácter ritual, que hasta la fecha se mantiene, fue acertada y no la aleja de nuestra interpretación, si consideramos que Blanco encontró también asas, probablemente de un «braserillo» o pátera; que se desconocian timiaterios o piezas de estructura similar al que presentamos; y que la mezcla y deformidad de los útiles incinerados con el difunto dificultaba el reconocimiento de otras partes.

Si paralelizamos el conjunto con una producción extrapeninsular, comprobamos que la disposición de cariátides soportando un contenedor para libaciones o quemador de esencias, responde al proceso de la sustitución y antropomorfización de símbolos de divinidades en objetos rituales y de ofrendas, que se desarrolla a partir de finales del siglo vil a.C. y que se documenta en el Mediterráneo oriental. A este fenómeno responde el perirrhanterion, gran recipiente de mármol con pedestal de tres o cuatro figuras femeninas, a veces con más de un metro de altura, cuyo tipo se deriva de Siria o Chipre y que, disperso en círculos de influencia griega, se ha documentado exclusivamente en santuarios como los de Isthmia (cerca de Corinto), Olimpia, Samos, Rodas, Delfos o Laconia (Boardman, 1978, 25 ss, figs. 74 y 75 ), donde eran depositados como ofrenda. Su forma puede ser contrastada con la crátera de bronce que Coleo de Samos y sus compañeros mandaron hacer con el diezmo de las ganancias obtenidas en Tarteso y que "consagraron en el Hereo sobre un pedestal compuesto por tres colosos de bronce ...hincados de hinojos»" (Heródoto, IV, 152). Quizás otra evidencia del origen oriental (sirio-fenicio) del formato sea la serie de figuritas montadas sobre animales (o partes de éstos) que se dicen siriofenicias y se datan en el siglo vil a.C.(Moorey, 1973). 
Una pervivencia de esos recipientes puede ser un quemaperfume en bronce hallado en una tumba del siglo va. ('., en Umm Udheinah (Aman), de quemador con tapadera de calados triangulares, sostenido por una cariatide con flor en la cabeza, mano sobre el vientre y túnica adornada en el cuello (Zayadine. 1985, 155, fig. 11). Todos estos paralelos deben ser considerados tanto por el formato como por su simbologia y función (cultual y funeraria). aunque lógicamente son de estilo y cronologias distintas.

Otros paralelos a las cariátides del timiaterio por la forma, el estilo egiptizante y la técnica de labrado (unque en piedra) son algunos exvotos femeninos dedicados en el templo de Afrodita de Golgoi en Arso (Chipre) y fechados en el siglo vi a.C. Son jovenes estantes vestidas con túnica similar a las peninsulares, que sostienen una flor de loto en la mano derecha (Cesnola, 1885, Iam X, 12; XXVI, 67: XXXIV, 213 y 214: Schürmann, 1984, XX, 8,9).

Considerando por último el quemador (figs. $14 \mathrm{y}$ 15), éste repite el perfil de la cazoleta del thymiaterion del Cerro del Peñón, el cual solamente dispone de 45 gallones y de un solo orificio central (Niemeyer y Schubart, 1965, 76, fig. 1) para la fijación al soporte. La morfologia responde al tipo de phiale mesomphalos en plata, bronce y cristal, derivado de prototipos fenicios y ampliamente documentado en contextos funerarios y santuarios del Mediterráneo oriental y Etruria desde el siglo vil a.C. (Strong, 1966, 67, fig. 17: Niemeyer, 1970; Gjerstad, 1948, 151, fig. 28, 7c).

Es posible que el quemador, como indica la forma de la arandela fijada en su borde, quedara finalmente cubierto por una tapadera similar a la de La Codosera, con triángulos calados y cérvido tumbado, y a la del timiaterio de Safara, con un toro encima (García y Bellido, 1957, 128-129; Almagro-Gorbea, $1977,246,247$, figs. 87-88). Tipo de tapadera al que podrian pertenecer también otras piezas aisladas como el ciervo de la colección Calzadilla, y los toros de Alcalá del Río (Olmos y FernándezMiranda, 1987, figs. 7 y 8 y 9) y de Cástulo (Blázquez, 1975, XCVI). Precisamente hemos creido identificar también un fragmento similar de tapadera calada en una de las amalgamas fundidas de la tumba de incineración castulonense de Estacar de Robarinas. La figura que coronaría la tapa sería el caballito en reposo, dotado de dos remaches, en realidad un ciervo con la cornamenta partida (Blanco, 1965,28 ). La tapadera calada ha sido identificada en uno de los trozos informes de bronce que se conserva en el Museo de Linares y que no figuraba en las láminas de la publicación.

Contrastando las semejanzas y diferencias mor- fo-técnicas del timiaterio de Villagarcia de la Torre con los peninsulares y extrapeninsulares, deducimos lo mismo que ya manifestamos para el grupo II de nuestra clasificación (Bandera y Ferrer, 1992) ante la pregunta sobre su centro de producción. Según nuestra valoración, apoyada también en piezas de orfebreria, se trata, sin duda, de una producción peninsular. propia de una fase avanzada del periodo orientalizante (mitad del siglo vi a.C.), en la cual una nueva generación de artesanos ha modificado los esquemas morfológicos de los prototipos orientales e introducido cambios, quizás ante la propia demanda de la población o por adaptación a verdaderos sincretismos religiosos (cariátides).

El diferente estilo que presentan las cariátides, modificados algunos elementos como la flor con tallo, las orejas y el vestido, en relación a la de Cástulo, da muestras de una mano o taller distintos. Sin embargo el formato de las figuritas indica la circulación de posibles modelos a partir de los cuales los broncistas sacaban moldes que después eran retocados según la pericia o gusto del artesano. Por otro lado la cazoleta, que modifica parcialmente la del timiaterio de El Cerro del Peñón (Málaga), y la utilización de garras en la base cónica (mezclando elementos de distintos tipos), nos animan a proponer la ubicación del centro de fabricación en la zona del sureste de la región extremeña, a lo que conducen también otros bronces orientalizantes (Bandera, 1994).

\section{ESTUDIO ICONOGRÁFICO DEL TIMIATERIO}

Durante las últimas décadas ha sido una constante la búsqueda de indicadores válidos entre las fuentes escritas y arqueológicas para poder determinar el tipo y grado de proyección de la religión y de los cultos orientales en la península ibérica a partir del periodo orientalizante. Fruto de este interés es la abundante bibliografia sobre el tema (Alvar, 1991; Blázquez, 1983; Id, 1993; Marin, 1976; Id, 1993). Creemos que la pieza que presentamos puede suponer una aportación valiosa en esta linea.

El conjunto completo constituye una unidad iconográfica en si desde la base hasta la cazoleta $y$, a la vez, cada parte tiene un valor iconológico propio de manera que forma un recorrido temático, con sentido ascendente, que culmina en el recipiente donde se quema el perfume.

El mundo vegetal y animal silvestre, que expresa la sacralidad del acto a través de una serie de especies (roseta, papiro, loto, león, ciervo, toro, entre otros), relacionadas también con el mundo de ultratumba, con la representación figurada de la di- 
vinidad y con la plasmación de sus atributos y de sus dominios, estả aquí representado de manera simplificada en la base del soporte.

Ejemplos iconográficos de esta relación divinidad-animales en el ámbito orientalizante peninsular lo constituyen, entre otros, el vaso de Valdegamas (Blanco, 1953; Olmos y Fernández-Miranda, 1987) y la dama de Galera (Marin, 1978, 28), donde la diosa Astarté está flanqueada por dos leones tumbados y dos esfinges respectivamente, lo que constituye una escena alegórica del poder que ejerce la diosa sobre la naturaleza (Olmos, 1992, 18). Pero en otras manifestaciones se abstrae considerablemente esta alegoria quedando reducida a pequeños animales colocados sobre los bordes del recipiente litúrgico, o bien a garras de felinos que sostienen otros símbolos de la diosa, como en los timiaterios de El Higuerón y Robarinas (Cástulo), La Joya y Villagarcia de la Torre.

Pero rara vez el artesano tartésico se limita a la representación de un sólo elemento alegórico, sino que, como en este caso, llega a extremos desorbitados. De forma que el recorrido iconográfico se continúa en el fuste adornado con lilas, interpretado como un tallo floral que soporta el altar de aromas consagrados (Culican, 1980). Es éste el elemento más frecuente entre los pebeteros hispanos y está ampliamente difundido por el Mediterráneo, no solo como objeto mueble sino con sus representaciones en sellos (Bandera y Ferrer, 1992, 57 ss.), en marfiles (relieve de Ninive representando las puertas del templo de Melkart en Tiro: Barnett, 1956, 87 ss.), en bronces (puertas de Balawat), en ediculas de terracotas y en estelas, determinando en todos los casos un lugar o función sacra (Moscati, 1988, 163; 649, 388).

No obstante, por si no estaba clara la alegoría, el artifice insiste coronando el fuste con las cariátides. La disposición de las figuras sosteniendo un lirio florecido simboliza la epifanía o manifestación de la divinidad a los hombres. Pero, por la indumentaria y por su número, representan más a jóvenes oferentes, a sacerdotisas consagradas al culto de Astarté, que un icono de la diosa misma, cuya presencia se manifiesta a través del perfume sagrado. $\mathrm{Y}$, por ello, creemos ver en este conjunto una materialización de cultos y rituales análoga a la que se produce en otros centros del Mediterráneo en torno al siglo vil a.C. y a la que responde tanto la producción de los perirrhanteria en santuarios griegos, como los exvotos de Arso (Chipre). En la peninsula ibérica esta antropomorfización debió arraigar por la presencia de orientales asentados en sus tierras, y conservarse en la tradición durante largo tiempo, siendo quizás una manifestación de este fenómeno las cariátides de Cástulo, Villagarcia y la de La Quéjola (Albacete). En todas ellas el vestido o la desnudez juvenil. la actitud oferente, la flor o la paloma que portan en la mano y su relación con el permufe la vinculan con el ámbito de Astarté/Afrodita, en el que servirian posiblemente como heteras o siervas de la diosa (Olmos y Fernández-Miranda, 1987, 213: Olmos, 1991, 99 ss.). El culto a esta divinidad se extendió por todo el Mediterráneo con las colonizaciones desde un arcaismo temprano, con una serie de rasgos comunes caracteristicos que se destacan de los posibles sincretismos con otros cultos locales anteriores (Grotanelli, 1981, 109-137; OImos, 1991, 103-104). La iconografia está documentada en los santuarios chipriotas dedicados a Afrodita/ Astarté, como el ya mencionado de Golgoi en Arsos, donde la diferencia con otros exvotos dedicados a una divinidad de la fertilidad más antigua del mismo santuario, se evidencia tan sólo en el estilo y en la técnica de elaboración.

Simbologia y función coinciden en los casos peninsulares, si bien en el ejemplar albaceteño, de cronología posterior, la estética helenizante se hace patente frente al modelo egiptizante más arcaico de los timiaterios de Cástulo y Villagarcia de la Torre, como también el estilo aqueménida modifica el de Amán.

Por último, la cazoleta, recipiente donde se queman las esencias como parte del ritual sacro donde los aromas personifican a la divinidad, en el caso del pebetero que nos ocupa, es en realidad una gran roseta, simbolo de Astarté, la germinación de una flor abierta que emite el olor sagrado.

\section{ANÁLISIS CONTEXTUAL Y FUNCIONAL}

La relación iconografia-función es difícil de analizar a partir de una documentación descontextualizada. Sin embargo, en lo que se refiere a los timiaterios peninsulares, sí hay suficientes elementos como para poder realizar un acercamiento interpretativo.

La lectura iconográfica de las partes y del todo sugiere, en este timiaterio extremeño, un conocimiento profundo del lenguaje simbólico y cultual de representaciones y atributos de divinidades orientales, en este caso las de Astarté, y por tanto muy distante de la posible interpretación de un artesano profano no familiarizado con la simbología religiosa oriental (o con una sincretización indigena); y aunque haya elementos que pueden estar representados según las corrientes estilísticas del momento, no faltan los componentes fundamentales de su contenido reli- 
gioso. Sin embargo por las circunstancias del hallazgo no hay seguridad en su adscripción a un contexto funerario o cultual, necesitando para ello la valoración de otros elementos en conjuntos contextualizados.

Fn el caso del thrmiaterion de la tumba 17 de La Joya, su pertenencia a un ajuar funerario es inequivoca ((jarrido, 1970, (iarrido y Orta, 1978, 49 ss.). En la composición de este ajuar, asi como en el de otras tumbas ( $n^{\circ} 5,9,16,18$, pozo A), están representados una serie de simbolos e iconografias alusivas a la divinidad funeraria: palmetas, flores de loto, cabezas hathóricas, granadas, felinos, cérvidos, rosetas, etc., en los objetos del servicio ritual (jarros, braserillos y fuentes) y en adornos personales o de tocador.

También a un contexto funerario pertenece el quemaperfumes de Los Higuerones (Cástulo, Jaén) pero, hallado dentro del túmulo y no en la tumba de pozo, ha sido interpretado como una ofrenda ritual. De este ejemplar cabe destacar por una parte el soporte del pebetero que mantiene la morfologia convencional del pie cónico y capitel de sépalos con la cazoleta, a la que se añaden tres animales sedentes; y por otra los restantes objetos que lo acompañaban en el depósito: una esfinge tocada con la corona real $\mathrm{y}$ un toro, ambos en actitud sedente y con remaches, que indican su sujeción al mismo o a un tipo parecido de recipiente (Blázquez, 1975; Blázquez y Valiente, 1982). A un entorno funerario análogo pertenece el ajuar de la incineración de Estacar de Robarinas donde se documentaron las figuras hathóricas. De la misma manera los símbolos están presentes en las urnas cerámicas que contenian las cenizas del difunto, decoradas con rosetas, lotos y palmetas simplificadas, motivos estrechamente relacionados con los pintados en los huevos de avestruz de Villaricos o en las cerámicas de Carmona (Blanco, 1965; Blázquez y Valiente, 1982), todos de nuevo en contexto funerario.

En otros enterramientos con igual o menor riqueza, también aparecen algunos de estos símbolos de Astarté, pero representados en ricos objetos de adorno personal como los de Aliseda, Sines (Bandera, 1987, 84, 296-354, nº193-195, lams. XX-XXI) y Villanueva de la Vera (González Cordero y otros, 1993, 249, lam.I), o en ajuares más humildes como el del conjunto $\mathrm{n}^{\circ} 2$ de la necrópolis de Aljucén (Mérida, Badajoz), donde se depositó un brazalete de bronce rematado con palmetas que repite la misma tradición de La Aliseda, Carmona, etc. (Enríquez y Domínguez, 1991, 39, fig. 5, 5).

Si bien todos estos timiaterios, por sus contextos e iconografia, podrían ser relacionados con una di- vinidad funeraria, existen también representaciones de los mismos simbolos en ámbitos no sepulcrales o mal contextualizados (Marin, 1976, 25 ss.).

La pata de felino del Museo Provincial de Cádiz. documenta un objeto ritual en el ámbito sacro de la Algaida. La identificación del yacimiento con el santuario de Phosphóros o Lux Duhia que describe Estrabón (III, 1,9) abre nuevas expectativas de análisis y de paralelos. La diosa venerada en este santuario al aire libre, Luz Divina (el planeta Venus en época romana - si bien el culto "oficial» en el santuario finalizó en el siglo $\|$ a.C.- - ) era la guia de navegantes y pescadores después del crepúsculo, cuando la luz solar habia desaparecido del horizonte. La doble advocación de conductora de los difuntos en el mundo de ultratumba y guía de los marineros durante la noche, creemos que puede sincretizarse en el culto a Astarté. Algunos exvotos del santuario pueden ser un argumentos en favor de esta identificación, como son las láminas de plata con ojos troquelados, identificadas normalmente como los «ojos de Astarté».

Un ejemplo análogo de thymiaterion asociado al culto de Astarté lo encontramos en el yacimiento submarino de Punta del Nao, donde algunos autores ubican el santuario de Venus Marina que menciona Avieno (Or. Mar. 310. Corzo, 1983; Escacena, 1986; Muñoz, 1990-91; Alvarez, 1992, 20-21), a partir de los depósitos supuestamente votivos, recuperados en los alrededores de La Caleta y de aquel accidente geográfico. Se trata del tripode de terracota decorado profusamente con palmetas, lotos y flores de lis que se agrupan formando un "árbol de la vida», sustentado por tres atlantes egiptizantes con el brazo sobre el pecho, y coronado por una gran palmeta de cuenco cercana a la boca del recipiente que expediria los perfumes rituales (Blanco, 1970, 54). La concepción simbólica, así como la cronología (siglo vı a.C.), lo relacionan con el ejemplar extremeño.

Por otro lado, el contexto del que procede el soporte de Alhonoz, aunque confuso, ha sido interpretado por algunos autores como una favissa ritual, perteneciente a una construcción del período orientalizante previa al gran edificio de época ibérica (Almagro-Gorbea y A. Domínguez, 1988-89; Bandera y Ferrer, 1992). La sacralidad del lugar puede quedar afianzada también por una lámina de plata decorada con los «ojos de Astarté» hallada en un recipiente cerámico del estrato $\mathrm{II}$, de época ibérica (López Palomo, 1981a; Id, 1981b: 91-92)

De lo expuesto se desprende que los escasos contextos arqueológicos fiables asocian estos objetos con un ámbito funerario (La Joya y los dos de Cástulo) o cultual (La Algaida, Punta del Nao) y 
que en los ajuares de ambos ambientes se representan unas iconografias de inspiración oriental que en su lugar de origen son de carácter simbólico y sagrado (Lagarce, 1991, 556). Los universos vegetal (roseta, palmeta, flor de lis, loto, papiro), animal (toro. ciervo, leones o esfinges) y humano (sacerdotisas) son los que encarnan a la divinidad y dan forma a un rito en una de cuyas facetas se queman plantas aromáticas.

En la iconografia oriental las tres especies pueden simbolizar a las diosas Hathor y Astarté (la Isthar sumeria). Sin embargo la fusión de las dos representaciones en una sola advocación, la de Astarté, está atestiguadá en Oriente, en Chipre, donde también se gesta el culto de Afrodita/Astarté (concretamente en Pafos) sincretizado con otros ritos a una divinidad de la fertilidad. Es con la conquista de esta isla por el faraón Amasis en el 570 a.C. cuando se populariza la iconografia de Hathor en vasos pintados, esculturas y capiteles de entornos sacros (Hermary, 1985; Karageorghis, 1991, 968; Beer. 1991. 357).

Sin embargo, si los contextos cultuales de la Algaida o de la Punta del Nao dejan lugar a pocas dudas sobre la función sacra de los objetos rituales alli depositados, los documentados en enterramientos pueden tener una doble lectura, bien como parte de un servicio ritual claramente oriental, o, según se ha expuesto a menudo (Aubet, 1977-78; Id, 1984), como objetos de prestigio indicadores tan sólo del estatus social privilegiado del difunto y de su poder adquisitivo. Ya hemos expresado anteriormente nuestra opinión al respecto (Bandera y Ferrer, 1992, 59-60), valorando la posibilidad de la presencia de individuos orientales, artesanos y/o comerciantes, que desarrollaban sus actividades en el entorno de las élites y que se enterrarian según sus creencias y ritos utilizando un servicio de vajilla tradicional.

Esta hipótesis puede acreditarse si tenemos en cuenta el uso de iconografias especificas en la liturgia funeraria, que, como ya hemos argumentado, gira en torno al universo de la Astarté fenicia. Lejos para nosotros de representar sólo una moda «orientalizante" potenciada por los colonizadores fenicios, la documentación de estas iconografias en enterramientos debemos relacionarla más bien con la advocación funeraria de esta diosa; como la que se inscribe en la Astarté de El Carambolo (Sevilla) interpretada por algunos autores como «Astarté de la gruta/tumba (funeraria)" y viendo en ella unas «pervivencias cananeas (ugariticas) en el culto fenicion (Olmo, 1991a, 367-372).

La advocación ttrt $h r$ (strt $h r$ en la estatuilla sevillana) traducida como "Astarté de la tumba» se basa según $(i$. del Olmo, en argumentos como los contextos regio-funerarios en los que siempre aparece esta advocación en los textos ugariticos y la función en la mitologia ugaritica de Anat/Ashtarte como "enterradora" de Baál. La diosa baja a los infiernos en busca de Baál para devolverlo a la vida. "conjugando asi de manera clara su relación con el mundo de los muertos y el de la fertilidad". EI carácter funcrario de la diosa no sólo queda puesto de manifiesto en la mitología oriental «sino también en el uso cúltico-funerario fenicio-púnico» al ser abundantes los contextos funerarios donde se documentan estatuillas de la diosa.

Un comentario aparte merece la tumba de incineración de Estacar de Robarinas y la composición de su ajuar. Junto con las urnas decoradas, el broche de cinturón o el timiaterio, el difunto se enterró con su panoplia de armas, espada y lanzas. Este ajuar funerario puede ser considerado como anómalo dentro del conjunto de enterramientos denominados «tartésicos orientalizantes" si atendemos a la integración de armas en él y a las caracteristicas tipológicas de éstas. La empuñadura de la espada, de antenas, con botón central y escotaduras laterales, y las lanzas (dos o tres), aunque fabricadas en hierro, guardan evidentes paralelismos tipológicos con la espada de Dalias (Almeria), con las armas de la Ria de Huelva, y con las grabadas en algunas estelas decoradas (concretamente la de Carmona), como ya señalara Blanco (1965, 35-36).

Se pueden distinguir, por tanto, en un mismo contexto dos tradiciones diferentes, una indigena $y$ guerrera de hondo arraigo y con origen en el Bronce Final y otra oriental que entierra a sus difuntos acompañados de objetos de culto. Un fenómeno de dualidad que se repite también en necrópolis de la periferia tartésica, como en El Carpio y en Las Fraguas en el valle del Tajo (Fernández-Miranda y Pereira, 1992, 71). En estos casos el rito oriental debió ser el predominante porque la mayoria de los factores que determinan el sepelio y el enterramiento, deposición bajo tierra, urnas con simbolos funerarios, servicio ritual, etc., son foráneos.

La contrapartida podemos verla en las estelas decoradas del SO. más recientes, en las que se continúa una práctica precolonial donde dominan los factores autóctonos: ausencia de enterramiento, ajuar de guerrero, lápida grabada, pero aparecen otros elementos de origen oriental (carros, espejos, peines,...; Ferrer y Mancebo, 1991). Podriamos hablar en algunos casos de mestizaje, en otros de fenómeno de difusión cultural, en otros incluso de modas seguidas por las élites para diferenciarse del resto de la sociedad, pero cada vez es menos discutible la pre- 
sencia en centros importantes, como en Cástulo, de individuos o grupos de orientales que se entierran según sus ritos de origen. Por ello creemos que la utilización conjunta de un servicio ritual y de una iconografia concreta, ambos referentes al culto funerario de Astarté en enterramientos considerados tartésicos, debe ser tomada como indice de definición cultural o, al menos, como una evidencia del tipo y origen de creencias y tradiciones del difunto sin que por ello éstas estuvieran generalizadas en el conjunto de la población.

\section{DISCUSIÓN Y SINTESIS}

A la hora de proponer una cronología de la pieza, si contamos exclusivamente con el análisis estilístico y con la relación de paralelos hispanos y extrapeninsulares, nos tendriamos que atener a una datación genérica dentro del período orientalizante, entre fines del siglo viII y el siglo vi a.C. (BanderaFerrer, 1993, 57-58). Sin embargo es posible una mayor aproximación cronológica siguiendo argumentos espaciales e iconográficos.

Por un lado, la localización del hallazgo en las cercanias de Llerena es indicativo de una serie de características compartidas por otros bronces orientalizantes extremeños. La zona sureste de la provincia de Badajoz es la que, durante la fase más avanzada del periodo orientalizante, recibe el influjo o la presencia directa de elementos procedentes del valle del Guadalquivir. Sin embargo la ruta frecuentada en estos contactos no se corresponde con la via utilizada durante el Bronce Final y la primera fase del periodo orientalizante. Esta última seguía el camino natural que comunicaba la costa atlántica con las tierras extremeñas y la Meseta norte mediante el curso del Guadiana (en un primer tramo), y con la falla de Plasencia y los puertos naturales de Béjar y Tornavacas que atraviesan las provincias de Badajoz y Cáceres. La ruta tenía sentido SO.-NE. y está bien definida por la abundancia de yacimientos y hallazgos que relacionan el área portuguesa y onubense con las submesetas (Alvarez y Gil, 1988; Ferrer, 1993, 186) y, según nuestra interpretación, explicaría la presencia de objetos orientalizantes tan al norte como el jarro de Coca (Segovia), el conjunto de Las Fraguas en Talavera (Toledo) y los materiales de Villanueva de la Vera (Cáceres).

Sin embargo, a partir del 600 a.C. este camino deja de ser frecuentado produciéndose un cambio de sentido, de dirección SE.-NO, por causas no del todo claras pero de consecuencias evidentes. A partir de este momento se intesifican los contactos con el valle del Guadalquivir en detrimento del área onubense. Las vias naturales seguidas coinciden con los valles excavados por los afluentes de la margen derecha del Guadalquivir, concretamente con el Ribera de Huéznar, donde se ubican Llerena y Villagarcía de la Torre, y con el curso del Guadiato, que pone en comunicación Córdoba con Medellin y donde Cancho Roano cobra sentido (Alvarez y Gil, $1988,315)$ en sus contactos con el área de Cástulo (Celestino, 1992).

Por otro lado, si nos apoyamos en la iconografía $y$ en su relación con Chipre y las costas sirias, hay que considerar que el tipo de Hathor tal como aparece en el timiaterio de Cástulo y en el bronce $\mathrm{Ca}$ rriazo está relacionado con el éxito de su iconografía a raiz de la conquista de Chipre por el faraón Amasis en el 570 a.C. Esta fecha puede ser utilizada como término post quem, a partir del cual justificar la presencia de estos motivos en el sur de la Peninsula, posiblemente ya en la segunda mitad del siglo vı a.C. Apoya esta misma cronología la serie de exvotos en piedra dedicados a la diosa Afrodita/ Astarté en templos chipriotas como el de Golgoi, datados en el siglo vı a.C., que, aunque fuertemente helenizados, repiten el esquema formal fenicio-egiptizante.

Otra cuestión planteada es la funcionalidad de estos objetos, sobre la que ya dejamos constancia de la dificultad que entraña este tipo de análisis por la escasez de contextos seguros y por el peligro que supone importar modelos foráneos exactos en la sociedad tartésica (Bandera y Ferrer, 1992). Sin embargo, partiendo de los escasos datos contextualizados, del análisis de los procesos técnicos y de la iconografia, llegabamos a la conclusión que los timiaterios tenían una función simbólico-religiosa y funeraria para la población colonial fenicio-púnica y, en el ámbito tartésico, posiblemente la misma, siendo un indicio de población orienta (artesanos metalúrgicos, orfebres, comerciante) relacionada con la élite tartésica (incluso se puede hablar de mestizaje) y asentada en los poblados del interior del valle del Guadalquivir, Extremadura y Levante.

Para apoyar esta hipótesis de comportamiento, disponemos en la actualidad de aportaciones teóricas, más o menos matizables, y datos arqueológicos dificiles de interpretar de otra manera, que unificados pueden avalar la teoría de la presencia y el establecimiento con carácter permanente de grupos emigrados de Oriente, concretamente del área siriopalestina.

Estamos de acuerdo con J. Alvar $(1991,354)$ en que «la presencia de objetos de culto fenicios en el interior, en ambiente indigena, no tiene porqué ser 
testimonio... de la aceptación de la religión fenicia por parte de los autóctonos, sino que puede ser sintoma de la presencia de fenicios asentados entre indigenas» y en que «la superestructura ideológica es menos proclive al cambio, pues es la estrategia destinada a preservar el sistema y darle coherencia en todos sus sentidos; por ello, se afirma que las prácticas funerarias son muy conservadoras) (Alvar, 1990, 25). En este sentido, para nosotros, la utilización de un programa iconográfico determinado o de unas imágenes de significación funeraria, como es el caso de las Astarté, en un contexto funerario tartésico, es indicativo de las creencias o tradiciones mantenidas por el enterrado y no sólo una moda o elementos de prestigio que realzan la categoria del personaje sepultado (Aubet, 1977-78; Id, 1984). De ser así, las élites (y otros grupos según la variedad de tipos de tumbas y ajuares) se enterrarían con cualquier objeto de elevado valor y acceso restringido, independientemente de su iconografia y de su función. Esta no parece ser la norma sino todo lo contrario.

La funcionalidad de los artículos que acompañan al difunto en la vida de ultratumba (jarras, «braserillos», timiaterios, marfiles decorados, huevos de avestruz) se puede enmarcar en lo que conocemos como el servicio ritual o en simbolos de vida y resurreción en el más allá (por ejemplo los huevos de avestruz) de inequívoco origen oriental.

Con respecto a la iconografia, ya hemos hecho referencia a cómo los universos vegetal y animal silvestres y el humano simbolizan los atributos y poderes de Astarté, o la misma adoración a la divinidad enterradora y resucitadora. Pero en el caso de las cariátides quizás tengamos en ellas una manifestación no sólo del culto a Astarté en el sur de la Península, sino también de la existencia más temprana de la hetería o prostitución sacra antes de su derivación profesionalizada conocida a través de la fuentes helenísticas y romanas (Olmos, 1991, 108). Serian el antecedente del timiaterio de La Quéjola, reflejo sin duda de la dispersión de ideas, creencias y costumbres por esa vía de comunicación antes mencionada del Guadiana con la cabecera del Guadalquivir y que fácilmente se introduciria en el sureste de la Meseta.

Así cuestionado, cobra sentido para nosotros la idea expuesta recientemente por algunos autores de que el considerado hasta ahora mundo funerario tartésico no es tal, sino los cementerios de colonos orientales instalados en el interior del valle del Guadalquivir (Belén y Escacena, 1992; Escacena, 1989; Id, 1992).
No creemos que debamos insistir más en esta argumentación, tema suficientemente debatido en favor de una auténtica colonización agricola (González Wagner, 1983 y 1986; Alvar-González. Wagner, 1988: González. Wagner y Alvar, 1989) o en contra (Carrilero, 1993). Pero si quisiéramos llamar la atención sobre algunos datos que implican la vigencia de una superestructura ideológica y. probablemente religiosa, de origen oriental, en puntos tan distantes como Cancho Roano o Montemolin.

Según las últimas interpretaciones, el palaciosantuario extremeño responde, por paralelos en planta y en funcionalidad, a un complejo donde las actividades económica, sagrada y residencial se compaginan, siguiendo modelos documentados en el norte de Siria (Almagro-Gorbea, 1993a; 1993b; AlmagroGorbea y Dominguez, 1988-89; Almagro-Gorbea y otros, 1990).

En Montemolín, los estudios más recientes, referidos sólo a la última construcción orientalizante (edificio D), han permitido documentar las actividades desarrolladas en sus dependencias y relacionarlas con el sacrificio de animales, partición y manipulación de carne, seleccionada según la especie y edad de la victima (Bandera y otros, 1994 e.p.). En conexión con este contexto se documentan, almacenados en una estancia, recipientes cerámicos con decoración pintada geométrica y figurativa $\mathrm{y}$ motivos iconográficos que nos son familiares: toros, grifos, esfinge, lotos, palmetas, rosetas (Chaves y Bandera, 1986; Id, 1993). Apuntamos sólamente, remitiéndonos a dicho estudio, que tanto en Grecia como en el área siriopalestina, el acceso al consumo cárnico debía ser precedido de un sacrifico ritual, donde las funciones religiosa, económica y alimenticia se enlazaban.

\section{REFERENCIAS BIBLIOGRÁFICAS}

AAA Anuario Arqueológico de Andalucia.

AEspA Archivo Español de Arqueologia.

$\mathrm{BPH}$ Biblioteca Prehistórica Hispana.

CuPAUAM Cuadernos de Prehistoria y Arqueología de la Universidad Autónoma de Madrid.

EAE Excavaciones Arqueológicas en España.

MB Madrider Beiträge.

MM Madrider Mitteilungen.

NAH Noticiario Arqueológico Hispánico.

RSF Rivista di Studi Fenici.

TP Trabajos de Prehistoria. 
Atmatiro-(jorl31 a, M. (1974): «Dos thymiateria chipriotas procedentes de la península ibérica» Miscelanea X.1\% aniversario de cursos de Ampuricis, 41-55. Barcelona.

- (1977): El Bronce Final yel periodo orientalizante' e'n Exrremadura. BPH XIV. Madrid.

- (1993a): «La organización palacial en la peninsula ibérican I' Coloquio de Lenguas y. Culturas Paleohispánicas. Colonia, 1989. Salamanca.

- (1993b): "Tarteso desde sus áreas de influencia: la sociedad palacial en la peninsula ibérica» en J. Alvar y J. M. Blázquez (Eds.) Los enigmas de Tarteso, 139-185. Madrid.

Almagro-Gorbea, M. y Dominguez, A. (1988-89): «El palacio de Cancho Roano y sus paralelos arquitectónicos y funcionales» Zephyrus XLIXLII, 339-382. Salamanca.

Almagro-GorbeA, M. y otros (1990): «Cancho Roano. Un palacio orientalizante en la península ibérica" $M M$ 31, 251-308. Madrid.

Alvar, J. (1990): "El contacto intercultural en los procesos de cambio" Gerion 8, 11-27. Madrid.

- (1991): «La religión como índice de aculturación: el caso de Tartessos" Atti del II Congresso di Studi Fenici e Punici 1, 351-356.

Alvar, J. y Gonzalezz Wagner, E. C. (1988): «La actividad agrícola en la economía fenicia de la peninsula ibérica» Gerión 6, 169-185. Madrid.

Alvarez Rojas, A. (1992): "Sobre la localización del Cádiz fenicion" Boletín del Museo de Cádiz V, 17-30. Cádiz.

Alvarez, A. y Gil, J. (1988): «Aproximación al estudio de las vias de comunicación en el primer milenio antes de Cristo en Extremadura» TP 45 , 305-316. Madrid.

AuBet, M. ${ }^{\text {a }}$ E. (1977-78): «Algunas cuestiones en torno al periodo orientalizante tartésico" Pyrenae 13-14. Barcelona.

- (1984): «La aristocracia tartésica durante el Período Orientalizante» Opus III, 445-468.

Bandera, M. ${ }^{\text {a }}$ L. de la (1987): La Joyeria Orientalizante e Ibérica del s.VII al s.I a.C. (Mitad Sur Peninsular). Sevilla

BANDERA, M. ${ }^{a}$ L. de la (1994) : "Técnica y sociedad prerromana". Arqueologia en el entorno del Bajo Guadiana. Actas del I Encuentro Internacional de Arqueologia del Suroeste. (Huelva 1993), 415439.

Bandera, M. a L. de la; Chaves, F.; Ferrer, E. y Bernaldez, E. (1994 e.p.): «El yacimiento tartésico de Montemolín" Congreso Tartessos. 25 años después (1968-1993). Jerez.

Bandera, M a L. de la, y Ferrer, E. (1992 e.p.): «Thymiateria orientalizantes en bronce. Nuevas aportaciones y consideraciones" Homenaje al Prof. Presedo Velo, 43-60. Sevilla.

BARNE:TT, R. D. (1956): "Phoenicia and the Ivory traden Archaeology 9, 27 ss.

Bitr, C. (1991): «Cultes chypriotes et éléments phéniciens?" Atti del II Congresso Internazionale di Studi Fenici e Punici 1, 357-365. Roma.

BHIIN, M. " y ESCACHNA, J. L. (1992): "Las comunidades prerromanas de Andalucia Occidental» Paleoetnologia de la Peninsula Itérica. Complutum 2-3, 65-87. Madrid.

Blanco, A. (1953): «El Vaso de Valdegamas y otros jarros de bronce del Mediodía español» AEspA 36. Madrid.

- (1965): «El ajuar de una tumba de Cástulo» Oretania 19. Jaén.

Blanco, A. y Corzo, R. (1983): «Monte Algaida. Un santuario púnico en la desembocadura del Guadalquivir" Historia $16 \mathrm{n}^{\circ} 87$. Madrid.

Blanco, C. (1970): «Nuevas piezas fenicias del Museo Arqueológico de Cádiz» AEspA 43, 50-61. Madrid.

Blizquiz, J. M." (1975): Tartessos y los origenes de la colonización fenicia en Occidente. Salamanca.

- (1983): Primitivas religiones ibéricas. Madrid.

- (1993): "El enigma de la religión tartésica» en J. Alvar y J. M. a Blázquez (Eds.) Los enigmas de Tarteso. Madrid.

- (1986): «La colonización fenicia en la Alta Andalucía (Oretania), siglo vIII-Vı a.C.» RSF XIV, 1. Roma.

BlAzquez, J. M." y VAliente, J. (1982): «El poblado de La Muela y la fase orientalizante en Cástulo» $M B$ 8, 407-426.

BoARDMAn, J. (1978): Greek sculpture. The archaic period. Londres.

CARrIllero, M. (1993): «Discusión sobre la formación social tartésica» en J. Alvar y J. M. Bááquez (Eds.) Los enigmas de Tartessos, 163-185. Madrid

Celestino, S. (1991): «Nuevos jarros tartésicos de bronce en el sur peninsular» $M M 32,52-85$. Madrid.

Cesnola, L. P. di (1885): A descriptive Atlas of the Cesnola collection vol.I. Boston.

Chaves, F. y Bandera, M. ${ }^{a}$ L. de la (1986): «Figurlich verziete Keramik aus dem GuadalquivirGebiet. Die Funde von Montemolín (bei Marchena, prov. Sevilla)» $M M 27,117-150$. Madrid.

- (1993): «Problemática de las cerámicas pintadas orientalizantes en su contexto" $V$ Coloquio de Lenguas y Culturas Paleohispánicas. Colonia, 1989, 49-89. Salamanca. 
COR/O) SAN(H1:/, R. (1983): "Cádiz y la arqueología fenician. Anales de la Real Academia Provincial de Bellas Artes de Cádiz 1. Cádiz.

CoRZO, R. y TOSCANO, M. (1992): Las vias romanas de Andalucia. Sevilla.

Cul.tcan, W. (1980): "Phoenician incense stands" Oriental studie's presented to B.S.J.Iserlim. Leiden.

Enriqutz, J. J. y Domincith/, (. (1991): «Restos de una necrópolis orientalizante en la desembocadura del río Aljucén (Mérida, Badajoz)" Saguntum 24, 35-52. Valencia.

Escactena Carrasco, J. L. (1986): "Gadir» Los fenicios en la peninsula ibérica, 39-58. Sabadell.

- (1989): «Los Turdetanos o la recuperación de la identidad perdidan Tartessos. Sabadell.

- (1992): «Indicadores étnicos de la Andalucía prerromana» Spal 1, 321-343. Sevilla.

Firnández-Miranda, M. y Pereira, J. (1992): «Indigenismo y orientalización en la Tierra de Talavera" Actas de las $1^{a}$ Jornadas de Talavera de la Reina y sus tierras, 57-95. Toledo.

Firrer Albelda, E. (1993): Nuevos documentos arqueológicos para la definición del horizonte Orientalizante en la peninsula ibérica: las puntas de flecha. Tesis de Licenciatura (inédita). Sevilla.

Ferrer, E. y Mancebo, J. (1991): «Nuevos elementos de carros orientalizantes en la Alta Andalucía. Algunas precisiones en torno a su función, significado y distribución" CUPAUAM 18, 113148.

García y BELLIDO, A. (1957): «El jarro ritual lusitano de la Colección Calzadilla" AEspA 30. Madrid.

GarRIDO Roíz, J. P. (1970): «Excavaciones en la necrópolis de «La Joya», Huelva ( $1^{\mathrm{a}}$ y $2^{\mathrm{a}}$ campañas)» $E A E 71$. Madrid.

Garrido, J. P. y Orta, E. M. ${ }^{\text {a }}$ (1978): «Excavaciones en la necrópolis de La Joya. Huelva II» $E A E$ 91. Madrid.

Gjerstad, E. (1948): Swedish Cyprus Expedition IV.

González Cordero, A.; de Alvarado, M. y BlanCo, J. L. (1993): «Las joyas orientalizantes de Villanueva de la Vera (Cáceres)», TP 50, 249. 262.

GONZÁlez WAGNER, E. C. (1983): «Aproximación al proceso histórico de Tartessos» AEspA 56, 3 ss. Madrid.

- (1986): «Notas en torno a la aculturación de Tartessos» Gerión 4. Madrid.

Gonzalez Wagner, E. C. y Alvar, J. (1989): «Fenicios en Occidente: la colonización agrícola» RSF XVII, 61-102. Roma.
Geovsllt1.. (i. (1981): "Santuari e divinita delle colonie fenici d'Occidenten La religion fenicia. Matrici orientali e sviluppi occidentali, 109-137. Roma.

KARAGitorgitls, V. (1991): "Amathus between the Greeks and the Phoenicians". Atti del I/ Congresso Internationale di Studi Fenici e Punici III, 959. 968. Roma.

LAcisRC1, E. (1991): "Le rôle d'Ugarit dans l'élaboration du répertoire iconographique syro-phénicien du premier millénaire avant J. C.n Atti del II Congresso Internationale di Studi Fenici e Punici I, 547-561. Roma.

LopH. PALOMO, L. A. (1979): La cultura ibérica del valle medio del Genil. Córdoba.

- (1981a): «Bronces y plata tartésicos de Alhonoz y su hinterland» Zephyrus XXXII-XXXIII, 245 ss. Salamanca.

- (1981b): «Alhonoz. Excavaciones de 1973 a 1978» N.AH 11. Madrid.

MANCHBo, J. y FERRIR, E. (1988-89): «Aproximación a la problemática de las puntas de flecha en época orientalizante. El yacimiento de Pancorvo (Montellano, Sevilla)" Zephyrus XLI-XLII, 315330. Salamanca.

- (1992): «El escarabeo de Pancorvo, Sevilla» Spal 1, 313-320. Sevilla.

Marin Cfiballos, M. ${ }^{a}$ C. (1978): «Documents pour l'étude de la religion phénico-punique dans la Péninsule Iberique: Astarté» II CIEMO. Argel.

- (e.p.): «Reseña bibliográfica sobre la religión fenicio-púnica en España. 1980-1993».

Maroto, M. (1990): Fuentes para el estudio de la Arqueologia en la provincia de Toledo. Toledo.

Moorey, P. R. S. (1973): Levant V, 83-99.

Moscatı, S. (1988): I Fenici. Milán.

MuÑoz, A. (1990-91): «Las cerámicas feniciopúnicas de origen submarino del área de La Caleta (Cádiz)» Cuadernos de Prehistoria y Arqueologia Castellonense 15, 287-333. Castellón.

Niemeyer, H. G. (1970): «Zum Thymiaterion von Cerro del Peñón» $M M$ 11,96-101. Madrid.

Niemeyer, H. G. y Schubart, H. (1965): «Ein ostphönikisches Thymiaterion von Cerro del Peñón (Almayate Bajo, prov. Málaga)» MM 6, 74-93.

Olmo, G. DEL (1991 a): «Pervivencias cananeas (ugaríticas) en el culto fenicio.I" Atti del II Congresso Internazionale di Studi Fenici e Punici I, $367-$ 372.

Olmos, R. (1991): «Puellae gaditanae»: ¿Heteras de Astarté?» AEspA 64, 99-109.

Olmos, R. y Fernández Miranda, M. (1987): «El 
timiaterio de Albacete" AEspA LX, 211-219. Madrid.

OrIA, M. y otros (1990): El poblamiento antiguo en la sierra sur de Sevilla. Zona de Montellano. Sevilla.

SchermanN, W. (1984): "Katalog der kyprischen Antiken in Badischen Landesmuseum Karlsruhe» Studies in Mediterranean Archaeology XX, 9.
Strongi, D. E. (1966): «Greek and Roman gold and silver platen. Londres.

Velasco, F. y otros (1990): "Avance a la carta del término municipal de Montellano» AAA 1987. 151-156. Sevilla.

ZaYadine, F. (1985): «Une tombe du Fer II à Umm Udheinah», Syria LXII, 155.

\title{
APÉNDICE \\ ESTUDIO ARQUEOMETALÚRGICO DEL TIMIATERIO
}

POR

\author{
S. ROVIRA LLORENS \\ Museo de América. Madrid.
}

No es frecuente que se produzcan hallazgos de objetos tan interesantes como el timiaterio de época orientalizante cuyo estudio analítico ahora encaramos. La compleja estructura vista en su despiece y la composición de las aleaciones de las partes integrantes son un excelente compendio de la tecnología de taller del artesano broncista que dio cuerpo a este objeto litúrgico.

\section{LAS ALEACIONES}

Para la determinación de la composición de las aleaciones se ha empleado la técnica espectrométrica no destructiva por fluorescencia de rayos- $x^{5}$ cuyos análisis se anotan en la tabla adjunta (fig. 19).

Los resultados ponen de manifiesto el empleo sistemático de bronce ternario, es decir, una aleación de cobre, estaño y plomo. Como es bien sabido, los bronces plomados tienen especial interés para

\footnotetext{
S Se ha utilizado un espectrómetro Keves Mod. 7000, con una fuente anular no colimada de ${ }^{241} \mathrm{Am}$. La superficie del detector es de $80 \mathrm{~mm}^{2}$. Una breve descripción de la técnica se encuentra en, S. Rovira, 1985.
}

el fundidor porque la presencia de plomo amplia considerablemente el intervalo de solidificación de la colada y ello permite que el metal fundido, al mantener una fase líquida durante más tiempo, se adapte mejor al relieve interno del molde, reproduciendo con mayor fidelidad el modelo. Pero tienen, en cambio, el inconveniente de su menor resistencia mecánica, lo que provocó ya de antiguo la fractura de la base del trípode que soportaba todo el peso del conjunto. Ello se debe a que el plomo, por ser muy poco soluble en el cobre fundido, queda segregado al solidificar $y$, por tratarse de un metal blando y facilmente deformable, allí donde se han formado segregados de plomo la aleación ofrece menor resistencia mecánica.

Una primera cuestión que cabe plantearse es si todo el metal empleado es fruto de un proceso de preparación único o, por el contrario, el fundidor preparó varias coladas. Para ello es necesario estudiar el reparto de los componentes mayoritarios, tratando de averiguar si existe alguna norma entre ellos. No conviene, sin embargo, utilizar las cifras absolutas de la composición sino relativizarlas con respecto al $100 \%$ de cobre, que es el componente principal, y con ello evitaremos la influencia mutua de estaño 


\author{
TIMATERION \\ Resultados de los análisis ( $\$$ en peso) \\ Técnica: Espectrometría por fluorescencia de rayos $x$ \\ Análisis de la superficie en área grande \\ Espectrónetro KEVBX Mod. 7000 del I.C.R.B.C. (Madrid)

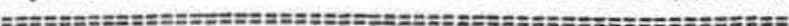

NUKERO DE

\begin{tabular}{|c|c|}
\hline ANALISIS & ZONA NHALIZADA \\
\hline PA4183A & Timaterion/exterior fuste \\
\hline PA4183B & Tinaterion/interior fuste \\
\hline PA4183C & Tinaterion/fuste inferior \\
\hline PA4183D & Tinaterion/aro con figuras \\
\hline PA41838 & Timaterion/cabeza figura \\
\hline PA4183P & Tinaterion/falda figura \\
\hline PA4183G & Tiwaterion/soporte figura \\
\hline PA4183B & Tinaterion/fuste superior \\
\hline PA4183I & Tinaterion/loto superior \\
\hline PA4183J & Tilaterion/loto internedio \\
\hline PA4183K & Tizaterion/loto inferior \\
\hline PA4183L & Tiaterion/tapa recipiente \\
\hline PA4183M & Tilaterion/recipiente \\
\hline$P \lambda 4183 \mathrm{~N}$ & Tinaterion/base \\
\hline PA41830 & Tinaterion/refuerzo base \\
\hline PA4183P & Tinaterion/base \\
\hline
\end{tabular}

\begin{tabular}{lll}
$\mathrm{Pe}$ & $\mathrm{Ni}$ \\
\cline { 1 - 1 } & & 0.12 \\
0.21 & 0.08 \\
0.36 & 0.12 \\
0.24 & 0.14 \\
0.29 & 0.13 \\
0.29 & 0.19 \\
0.22 & 0.12 \\
0.24 & 0.09 \\
0.27 & 0.10 \\
0.26 & 0.12 \\
0.24 & 0.17 \\
0.28 & 0.18 \\
0.40 & 0.11 \\
0.22 & 0.12 \\
0.30 & 0.19 \\
0.36 & 0.13
\end{tabular}

Cu an
78.09 nd
78.09 nd
81.33 nd
80.61 nd
81.05 nd
79.87 nd
80.84 nd
76.43 nd
75.18 nd
76.73 nd
76.15 nd
78.87 nd
82.69 nd
80.77 nd
71.47 nd
80.23 nd

As
nd
nd
nd
nd
nd
nd
nd
nd
nd
nd
nd
nd
nd
nd
nd
nd

\begin{tabular}{|c|c|c|c|c|}
\hline$\lambda g$ & $\mathrm{Sn}$ & $\mathrm{Sb}$ & $\mathrm{Pb}$ & $\mathrm{du}$ \\
\hline$\overline{0.040}$ & $\overline{11.61}$ & 0.017 & 9.68 & -- \\
\hline 0.038 & 10.13 & 0.015 & 11.33 & -- \\
\hline 0.027 & 12.96 & 0.007 & 5.08 & -- \\
\hline 0.056 & 13.10 & 0.010 & 5.73 & - \\
\hline 0.047 & 12.47 & 0.009 & 5.60 & - \\
\hline 0.052 & 13.64 & 0.011 & 5.84 & - \\
\hline 0.063 & 12.60 & 0.019 & 6.02 & - \\
\hline 0.056 & 15.05 & 0.019 & 8.01 & - \\
\hline 0.069 & 14.34 & 0.016 & 9.92 & - \\
\hline 0.045 & 16.73 & 0.010 & 5.99 & -- \\
\hline 0.052 & 16.80 & 0.005 & 6.48 & - \\
\hline 0.106 & 5.82 & 0.075 & 14.56 & - \\
\hline 0.014 & 12.18 & 0.005 & 4.49 & - \\
\hline 0.030 & 11.63 & 0.006 & 7.14 & - \\
\hline 0.025 & 7.86 & 0.016 & 20.03 & - \\
\hline 0.025 & 13.05 & 0.010 & 6.09 & - \\
\hline
\end{tabular}

- : Blevento ausente o no buscado

nd : Blenento no detectado

tr : Blemento presente como trazas no valorables

det: Blenento detectado pero no valorado por carecer de patrones adecuados

Figura 19.- Resultado de los analisis practicados al timiaterio de Villagarcia de la Torre.

y plomo en el cálculo de las proporciones. A manera de ejemplo, considerando el análisis PA4183A, la proporción de estaño referida al $100 \%$ de cobre es $14,87 \%$ y la de plomo $12,39 \%$, mientras que las cifras reales referidas al $78,09 \%$ de cobre son 11,61 y $9,68 \%$ respectivamente (valores de la tabla). El cuadro I (fig. 20) representa gráficamente los cocientes $100 /[\mathrm{Sn}]$ y $100 /[\mathrm{Pb}]^{\circ}$, es decir la cantidad proporcional de estaño y plomo que el fundidor añadió en cada caso a una cantidad dada de cobre. En la columna del estaño aparecen dos agrupamientos en torno a los valores 5 y 6 , y unos pocos puntos dispersos, lo cual parece indicar dos tipos básicos de liga cobre-estaño caracterizadas por la adición de aproximadamente $1 / 5$ ó 1/6 de estaño a una cantidad dada de cobre?

Pero los bronces ternarios, contienen también

\footnotetext{
'El simbolo encerrado entre corchetes significa la concentración de ese elemento con relación al $100 \%$ de cobre.

'Asumimos que el artesano utilizaba relaciones ponderales para calcular las cantidades a fundir, en lugar de los porcentajes.
}

plomo. En el mismo cuadro I (fig. 20) se observa una distribución mucho más aleatoria del contenido de plomo, que conviene explicar en función del comportamiento de los metales en disolución ${ }^{\times}$. La rutina de trabajo aconseja fundir primero el cobre y el estaño, obteniendo un bronce binario con un determinado coeficiente 100/[Sn], y añadir luego el plomo. Como se ha dicho, la solubilidad del plomo en el cobre es baja, quedando segregado. Debido a la mayor densidad del plomo, tiende a bajar lentamente hacia el fondo del crisol, resultando asi una una aleación poco homogénea ${ }^{\circ}$. Cuando el metal líqui-

\footnotetext{
* No podemos entrar en detalle aqui en estas cuestiones de indole fisico-quimica, que se estudian mediante los anagramas de fases correspondientes, consultables en cualquier manual de metalurgia teórica, en el capitulo de termodinámica de las aleaciones.

" La cinética de estas disoluciones es compleja y tiene que ver, entre otros mecanismos, con la formación de las redes cristalográficas al solidificar. Como la solubilidad entre el estaño y el plomo es grande en estado liquido, una parte del estaño presente será arrastrada por el plomo. En relación con estas cuestiones véase, por ejemplo, la obra de Scott (1991).
} 
do del crisol se vierte en varios moldes, las piezas resultantes mostrarán tasas medias de plomo distintas a pesar de proceder de la misma colada, mientras el coeficiente 100 /[Sn] se mantendrá más estable dentro de ciertos limites de variabilidad. Asi se explica la mayor dispersión de los valores del plomo en el cuadro 1 (fig. 20) cuando los del estaño tienden a un cierto agrupamiento.

En el cuadro 2 (fig. 21 ) se ha reflejado la correlación entre los valores relativos de estaño y plomo de cada análisis. La existencia de varios tipos de aleación ( $A, B, C$ y D) es evidente y ello indica la preparación de diferentes coladas. Es probable que la aleación A fuera, a su vez, subdivisible en dos o más (por una cuestión de volumen de metal), pero se hallan tan próximas en términos cuantitativos que la mejor interpretación sugiere la preparación de dos o más coladas con los mismos ingredientes.

La identificación de los puntos del cuadro 2 (fig. $21)$ permite conocer las partes del thymiaterion elaboradas con cada colada:

\begin{tabular}{|c|c|}
\hline \multicolumn{2}{|l|}{ Aleación A: } \\
\hline PA4183P & Base tripode \\
\hline PA4183N & Base trípode \\
\hline PA4183C & $\begin{array}{l}\text { Fuste liso (forma cuerpo con } \\
\text { la base) }\end{array}$ \\
\hline PA4183A y B & Fuste torneado \\
\hline PA4183D a G & Conjunto de figuras \\
\hline \multicolumn{2}{|l|}{ Aleación B: } \\
\hline PA4184H & Corona superior del fuste \\
\hline PA4184I & $\begin{array}{l}\text { Flor superior (forma cuer- } \\
\text { po con la corona) }\end{array}$ \\
\hline PA4 184J & Flor central \\
\hline PA4184K & Flor inferior \\
\hline PA41840 & Refuerzo interno de la base \\
\hline
\end{tabular}

Aleación C:

PA4184L

Tapa del recipiente superior

\section{Aleación D: PA4184M}

\section{Recipiente superior}

El estudio de ciertos constituyentes menores y oligoelementos de la aleación como la plata y el antimonio también puede ser de ayuda para confirmar los tipos de aleación. Así, en el cuadro 3 (fig. 22) se han representado las concentraciones de $\mathrm{Ag}$ y $\mathrm{Sb}$, encontrando que los bronces A y B forman una nube común, mientras que los $\mathrm{C}$ y $\mathrm{D}$ se separan claramente del grupo. Ello significa, además, que

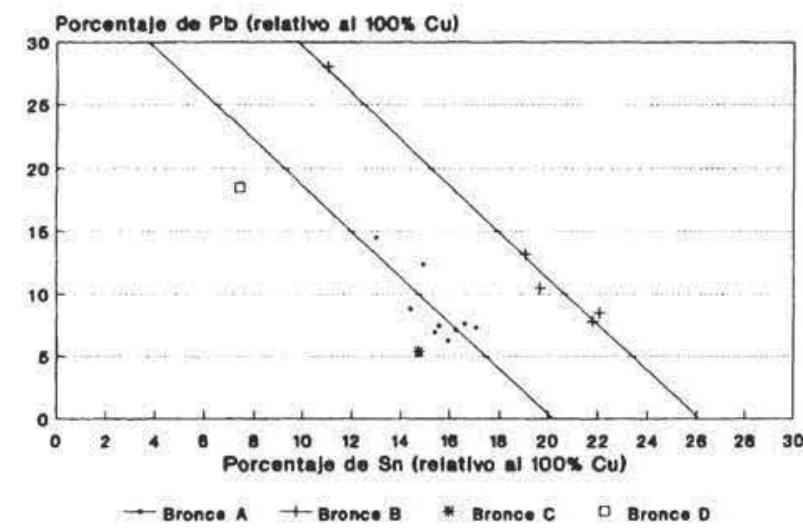

Figura 20.--Cuadro 1. Proporciones relativas de estaño y plomo ligadas con el cobre.
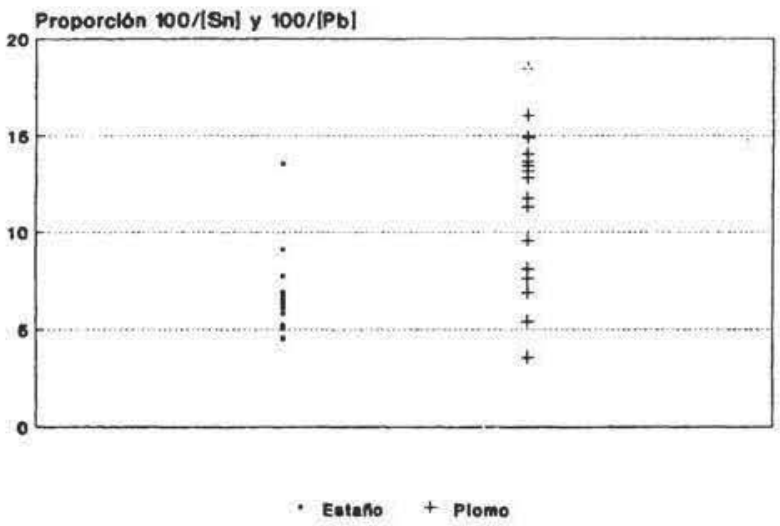

Figura 21.-Cuadro 2. Correlación entre los valores de estaño y plomo de cada análisis.

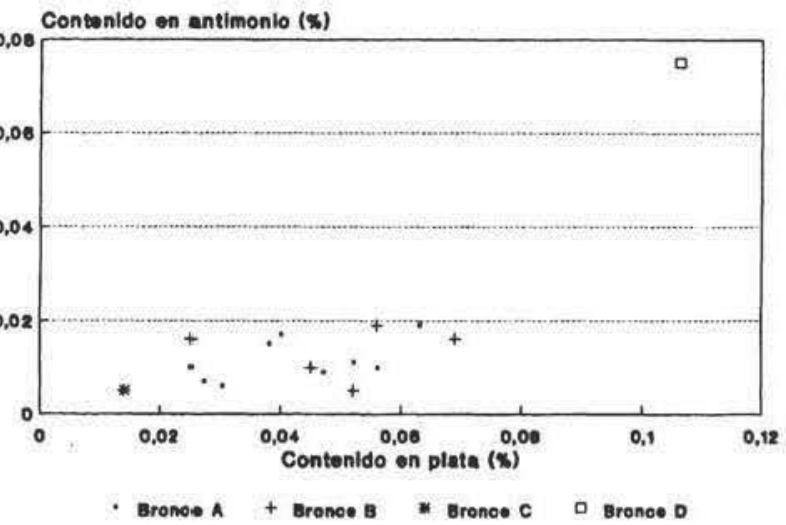

Figura 22.-Cuadro 3. Concentraciones de plata y antimonio en cada uno de los cuatro bronces. 
la materia prima de partida (el cobre, pues es el responsable principal del aporte de menores constituyentes) es la misma para los bronces A y B, y diferente para los C y D.

Todos estos pequeños detalles del estudio arqueometalúrgico son importantes para conocer mejor los procesos de taller. El fundidor disponia de crisoles con una capacidad limitada, adecuada al rendimiento óptimo de su manera de trabajar. Como es sabido la preparación de una colada comporta un gasto de materias primas y de combustible para fundirlas; cuanto mayor es la masa de metal, mayor es el consumo de combustible. Pero hay una limitación dada por la capacidad calórica del carbón y el tamaño y condiciones del hogar o mufla empleado. Si la masa a fundir es excesiva, el consumo de combustible es muy superior al teórico debido a las pérdidas y disipaciones del sistema y al mayor tiempo necesario para la fundición. Por otra parte, con cantidades de metal fundido grandes el crisol se maneja con mayor dificultad cuando se ha de aplicar al relleno de muchos moldes de pequeña capacidad. El tiempo requerido para la operación también es mayor y puede hacer que parte del metal solidifique en el propio crisol, aumentando las pérdidas. Por estas razones, el fundidor experto calcula con precisión la cantidad de metal en función de un tamaño rentable de crisol y de un número determinado de moldes por colada. Asi se explican las diferentes coladas observadas en el thymiaterion que nos ocupa que, probablemente, remitirian a cantidades relativamente similares a excepción de la tapa del recipiente.

\section{LOS BRONCES ORIENTALIZANTES}

Pocas son las investigaciones llevadas a cabo acerca de las aleaciones de piezas orientalizantes halladas en la Peninsula, reducidas prácticamente a dos trabajos: uno relativo a los bronces tartésicos de la Necrópolis de la Joya, Huelva (Escalera, 1978) y otro dedicado a la bandeja sevillana encontrada en El (jandul (Rovira 1989)" "'onviene traer a colación, en primer lugar, el thrmiaterion de La Joya, con algún paralelo formal con el que nos ocupa como las tres flores de loto del fuste o los pies rematados en garras de felino. El único análisis publicado formula un bronce binario pobre $197,05 \%$ C u, 2.6\% $\mathrm{Sn})$, pero no sabemos a qué pieza del montaje coresponde (Escalera 1978. 216, 227), probablemente a alguno de los platillos forjados pues este tipo de aleación resulta muy conveniente para conformar chapas de bronce "I.

Si por la via analítica no es posible establecer comparaciones con el ejemplar de La Joya, no por ello las aleaciones encontradas en la pieza extremeña resultan chocantes en el conjunto de los materiales tartésicos conocidos, donde las piezas de fundición suelen ser bronces ternarios con formulaciones muy diversas, respondiendo esta apreciación a un uso tecnológico muy común en toda el área mediterránea (Rovira 1989, 223).

\section{REFERENCIA BIBLIOGRÁFICA}

Escalera Ureña, A. (1978): «Examen de laboratorio de los materiales de La Joya (Huelva)». En J. P. Garrido y E. M." Orta: «Excavaciones en la Necrópolis de la Joya (Huelva)", EAE, 96. Madrid, pp. 213-256.

ROVIRA LLOREnS, S. (1985): «Métodos analiticos aplicados al estudio y conservación de materiales arqueológicos». Revista de Arqueología, 47, pp. 13-19.

- (1989): «Examen de laboratorio de la fuente de El Gandul (Sevilla)". AEspA, 62, pp. 219-225.

Scott, D. A. (1991): Metallography and Microstructure of Ancient and Historic Metals. The Getty Conservation Institute. Los Angeles.

1" Tenemos en curso el estudio de laboratorio de los materiales metálicos de Cancho Roano (Villanueva de la Serena, Badajoz), propiciado por las gestiones del profesor Sebastian Celestino y con la entusiasta colaboración de Guillermo Kurtz, director del Museo Arqueológico de Badajoz. Con él se ampliará sustancialmente el repertorio de análisis de piezas orientalizantes.

"También son bronces pobres la bandeja de El Gandul y algunas otras piezas de La Joya. 